\title{
Enhanced Mechanical and Durability Performances of Low Cement Concrete with Natural Pozzolan Addition
}

\author{
Keila Robalo ${ }^{1}$, Hugo Costa ${ }^{2 *}$, Ricardo do Carmo $^{3}$ and Eduardo Júlio ${ }^{4}$
}

\begin{abstract}
The decarbonization of concrete structures sector is a priority due to the world climate. Since Portland cement is responsible for approximately $7 \%$ of the anthropogenic emissions worldwide, it is decisive to partially replace it by products with lower environmental impact. Fly ash has become highly demanded, due to its proven advantages, however, has announced end by the developed countries. The purpose of this research is to develop and characterize low cement concrete (LCC) with natural and ecological pozzolan additions as an alternative to fly ash. The main objectives are: define several structural concrete mixtures with low cement dosage, ranging from 125 to $175 \mathrm{~kg} / \mathrm{m}^{3}$; characterize the workability and the mechanical properties, beyond the durability performance of those concretes; study the influence of pozzolans additions on LCC performance, as an alternative to fly ash; assess the service life of structures produced with the developed LCC. It is possible to produce LCC with natural pozzolan additions, instead of fly ash, with improved mechanical properties and enhanced durability performances. Results also show that the structural LCC produced with pozzolan from Cape Verde provide a great protection against steel corrosion, achieving values $50 \%$ higher than concrete with fly ash, and even higher margins when compared with the minimum concrete covers recommended by standards, which highlights the benefits of its use from the sustainability point of view.
\end{abstract}

\section{Introduction}

The development of more eco-efficient concretes is encouraged by the need to assure higher sustainability in the concrete construction sector. One way to develop these concrete solutions is to reduce the environmental impact regarding concrete production since more than $10 \times 10^{9}$ tons of concrete are produced annually and Portland cement accounts for approximately $7 \%$ of the $\mathrm{CO}_{2}$ released into the atmosphere (Meyer 2009). The production of eco-efficient concrete with low cement content (LCC) in its formulation contributes to increasing the sustainability of concrete structures, because the use of clinker proportion is significantly reduced compared to current concrete, and also due to the advantages of using industrial wastes or by-products, such as partial replacement of the former (Fennis et al. 2009; Fennis and Walraven 2012). Published works on this subject indi-

${ }^{1} \mathrm{PhD}$. Student, University of Cape Verde, CERIS \& Instituto Superior Técnico - Universidade de Lisboa, Av. Rovisco Pais 1, 1049-001 Lisboa, Portugal.

${ }^{2}$ Professor, CERIS \& ISEC-Polytechnic Institute of Coimbra, Rua Pedro Nunes, Quinta da Nora, 3030-199, Coimbra, Portugal. *Corresponding author,

E-mail: hcosta@isec.pt

${ }^{3}$ Professor, CERIS \& ISEC-Polytechnic Institute of Coimbra, Rua Pedro Nunes, Quinta da Nora, 3030-199, Coimbra, Portugal.

${ }^{4}$ Full Professor, CERIS \& Instituto Superior Técnico Universidade de Lisboa, Av. Rovisco Pais 1, 1049-001 Lisboa, Portugal. cate that is possible to reduce significantly the amount of cement without changing the properties of the mixtures, thus reducing $\mathrm{CO}_{2}$ emissions per cubic meter of concrete by about 25\% (Fennis 2011; Fennis et al. 2009). The reduction of cement dosage, especially of the clinker portion, can be compensated, without compromising the specified properties for concrete, combining the granulometric optimization with the use of cement with high reactivity, using additions as cement substitute, and using powerful superplasticizers together with low water dosage, resulting in an increased packing density (Fennis et al. 2013a; Mehta and Monteiro 2014; Proske et al. 2014; Robalo et al. 2021).

The use of additions as cement substitute is sustainable if these additions have economic viability, are available in the market, and have also technical feasibility. The additions have similar characteristics to cement and those that have better environmental performance are natural and artificial pozzolans. Pozzolans contribute to reduce the global $\mathrm{CO}_{2}$ emissions and the concrete cost, improve the workability of fresh concrete and, in some cases, increase the durability of concrete. A great achievement in this regard is the development of concrete mixtures containing high volumes of fly ash (up to $50 \%$ or more of fly ash or biomass fly ash) (Bentz et al. 2011; Mehta 2004; Nasvik 2013; Robalo et al. 2021).

Fly ash is the most used type of artificial pozzolana in concrete production. It is a by-product from burning coal or even biomass that, when incorporated into concrete, promotes an increase of workability, reduces the hydration heat, increases the maximum strength, reduces the permeability, and, consequently, improves its durability (Bentz et al. 2011, 2012; Fennis 2011; Mehta 
2004). Some of these advantages are associated to its water-reducing property, which is related with the spherical shape and reduced specific surface of its fine particles (Fennis 2011; Mehta 2004). According to Jiang and Malhotra (2000), it is possible to obtain a reduction up to $20 \%$ of the water demand in concrete mixtures with high dosage of fly ash. However, this parameter is highly dependent on the quality of the fly ash and the amount of replaced cement.

Despite its numerous advantages, there are some limitations in relation to its use. According to Mehta (2004), the dosage of fly ash between $15 \%$ and $20 \%$ by weight of the total cementitious material is commonly used. Teixeira et al. (2018) recommend proportions up to $40 \%$ for the replacement of cement, since its use in large volumes presents some problems and one is the decrease of concrete $\mathrm{pH}$, which may increase the corrosion problem of steel rebars due to carbonation. However, some studies prove that with $50 \%$ or higher replacement, of cement by fly ash, it is possible to produce sustainable concrete with high workability, as well as both high strength and durability (Bentz et al. 2011; Mehta 2004; Nasvik 2013). It is further emphasized that the high dosages of fly ash are still not well accepted by the construction industry, since, when compared to traditional concretes, they present a slower hardening curve at younger ages (Cost and Aci 2011). Although, it is possible to obtain concrete with higher mechanical strengths at older ages due to the pozzolanic reactions, meaning those reactions are slow but prolonged (Fennis et al. 2009; Proske et al. 2014; Robalo et al. 2021).

Natural pozzolans are additions resulting from the rapid cooling of products from volcanic eruptions or in the form of diatomaceous earth. Their properties vary considerably, depending on their origin, due to the variable proportions of the constituents and to the different mineralogical and physical characteristics of the active materials. Natural pozzolans mixed with lime were used in concrete construction long before the invention of Portland cement to enhance the strength of concrete and mortar, but with the development of cement, its use decreased. Many structures of that ancient civilizations are still extant as a testament to the durability of limepozzolan mortars and concrete. Currently, those products are used with Portland cement not only for strength but also for economic and technical reasons, to take benefit of the modification of certain properties on fresh and hardened Portland-cement concrete (ACI Committee 232 2000). And, more recently, the natural pozzolans regained popularity as an environmentally sustainable alternative to produce concrete. Unlike fly ash and cement, the natural pozzolans do not need thermal energy, being instead to be ground to present pozzolanic activity, so their processing has less cost and less $\mathrm{CO}_{2}$ emission. The concrete with this type of addition has good mechanical properties and durability characteristics when compared with Portland cement concrete (Rodríguez-Camacho and Uribe-Afif 2002;
Uzal et al. 2007). According to Uzal and Turanli (2003), it is possible to obtain high-volume of natural pozzolan blended cement with comparable mechanical properties in late ages and excellent ability to reduce the alkalisilica expansion. Later, Uzal et al. (2007) also investigated the properties of concrete mixtures containing high volumes of natural pozzolan $(50 \%$ by mass of total cementitious materials) for structural applications, and the results showed that the high-volume of natural pozzolan concrete is suitable for structural applications, with 12 to $14 \mathrm{MPa}$ and 29 to $38 \mathrm{MPa}$ values of compressive strengths at 3 and 28 days, respectively.

\section{Research significance and objectives}

The main studies on the formulation and characterization of LCC are based essentially on the replacement of cement by fly ash and were clearly proven that the additions and formulation parameters have a high influence on concrete properties (Fennis et al. 2013a; Fennis and Walraven 2012; Proske et al. 2016; Robalo et al. 2021). However, there are no relevant studies on the addition of natural pozzolans to the LCC paste as an alternative to fly ash, as well as the respective influence on concrete performance. Therefore, it is necessary to carry out studies with other products (natural or industrial byproducts, preferably pozzolanic and eco-friendly) that can be used as partial replacement, not only of the Portland cement but also of the fly ash, contributing this way for the decarbonization of concrete. This alternative may also improve some limitations of using fly ash in concrete, like the possibility to increase the mechanical strengths at younger ages and the lower carbonation resistance. In this context, two natural pozzolans, from Cape Verde and the Azores, were selected as additions to the LCC paste, seeking to constitute a more sustainable alternative solution than those already developed with fly ash. The main objective of this research is to develop a low cement concrete (LCC) with natural pozzolan additions instead of fly ash, without compromising the specified mechanical properties of concrete and eventually enhance its durability. It is also intended to mitigate the limitation regarding the maximum proportion of natural pozzolan in cementitious components, $30 \%$ or less, that should be used in concrete mixtures for structural applications, which is defined to avoid the increase of mixing water demand and the lower rate of strength development (Uzal et al. 2007). To achieve this goal several mixtures combining the addition of different pozzolans and filler with the granulometric optimization, and the use of powerful superplasticizers were tested. The granulometric optimization and the use of superplasticizer allow to increase the packing density of the mixture and, consequently, reduce the need for water and binder content since there is less space available between particles (Fennis et al. 2013b; De Grazia et al. 2019). This contributes to improve the efficiency of the binder paste in strength and the durability performance 
Table 1 Chemical and physical compositions of PC, PA, FA and C.

\begin{tabular}{|c|c|c|c|c|c|c|c|c|c|c|c|c|c|c|c|}
\hline & $\begin{array}{c}\mathrm{LOI}^{1} \\
(\%)\end{array}$ & $\begin{array}{c}\mathrm{PAI}^{2} \\
(\%)\end{array}$ & $\begin{array}{c}\mathrm{SiO}_{2} \\
(\%)\end{array}$ & $\begin{array}{c}\mathrm{Al}_{2} \mathrm{O}_{3} \\
(\%)\end{array}$ & $\begin{array}{c}\mathrm{Fe}_{2} \mathrm{O}_{3} \\
(\%)\end{array}$ & $\begin{array}{c}\mathrm{CaO} \\
(\%)\end{array}$ & $\begin{array}{c}\mathrm{MgO} \\
(\%)\end{array}$ & $\begin{array}{c}\mathrm{SO}_{3} \\
(\%)\end{array}$ & $\begin{array}{c}\mathrm{K}_{2} \mathrm{O} \\
(\%)\end{array}$ & $\begin{array}{c}\mathrm{Na}_{2} \mathrm{O} \\
(\%)\end{array}$ & $\begin{array}{c}\mathrm{TiO}_{2} \\
(\%)\end{array}$ & $\begin{array}{c}\mathrm{P}_{2} \mathrm{O}_{5} \\
(\%)\end{array}$ & $\begin{array}{c}\mathrm{MnO} \\
(\%)\end{array}$ & $\begin{array}{c}\mathrm{SrO} \\
(\%)\end{array}$ & $\begin{array}{c}\text { Density } \\
\left(\mathrm{kg} / \mathrm{dm}^{3}\right)\end{array}$ \\
\hline PC & 8.33 & 79 & 46.18 & 16.44 & 6.30 & 6.11 & 3.09 & 0.01 & 4.19 & 5.80 & 1.91 & 0.41 & 0.26 & 0.08 & 2.23 \\
\hline PA & 5.67 & 75 & 55.96 & 17.87 & 5.61 & 3.93 & 0.97 & 0.21 & 3.89 & 4.02 & 0.94 & 0.10 & 0.26 & 0.02 & 2.38 \\
\hline FA & 3.90 & 81 & 54.0 & 22.0 & 8.5 & 6.0 & 1.6 & 0.0 & 1.6 & 1.0 & 1.2 & 0.8 & $<0,3$ & -- & 2.30 \\
\hline $\mathrm{C}$ & 1.30 & -- & 19.87 & 5.19 & 3.31 & 65.15 & 1.54 & 3.33 & 0.59 & 0.11 & -- & -- & -- & -- & 3.15 \\
\hline
\end{tabular}

${ }^{1}$ Loss on ignition; ${ }^{2}$ Pozzolanic activity index at 28 days.

of the LCC (Björnström and Chandra 2003; Fennis et al. 2013a, 2013b; Proske et al. 2014).

This research work is organized as follows: (i) define the LCC compositions and characterize the concrete with reduced cement dosage, between 125 and 175 $\mathrm{kg} / \mathrm{m}^{3}$, setting the powder dosage of the paste on 350 $\mathrm{kg} / \mathrm{m}^{3}$ to ensure good workability; also combined addition of class F fly ash and limestone filler was considered; (ii) study the influence of the addition of natural pozzolans (from Cape Verde and the Azores), as an alternative to fly ash, on workability, mechanical properties (tensile and compressive strengths and Young's modulus) and durability (capillary water absorption, electrical resistivity, carbonation, and chloride-ion penetration) on LCC; and (iii) assess the service life related with the risk of steel reinforcement corrosion of structures produced with the formulated LCC, taking into account the resistance to carbonation and the chlorides penetration obtained experimentally.

\section{Materials and methods}

\subsection{Concrete constituents}

The selection of materials for concrete production was made in order to obtain concrete with high packing density, good workability and performance. Thus, two siliceous sands ( $\mathrm{S} 0 / 1 \mathrm{~mm}$ and $\mathrm{S} 0 / 4 \mathrm{~mm})$ and two coarse aggregates (siliceous rolled gravel $\mathrm{G} 4 / 8 \mathrm{~mm}$ and crushed limestone CL6/14mm) were used, whose particle size curves are presented in Fig. 1. Portland CEM I 52.5R (C) cement, class F fly ash (FA), and limestone filler (LF) were used as binder powder on reference LCC mixtures. Fly ash was replaced by two types of natural pozzolans: from the Azores (PA) (Fig. 2b) and from Cape Verde (PC), (Figs. 2c and 2d), which was brought

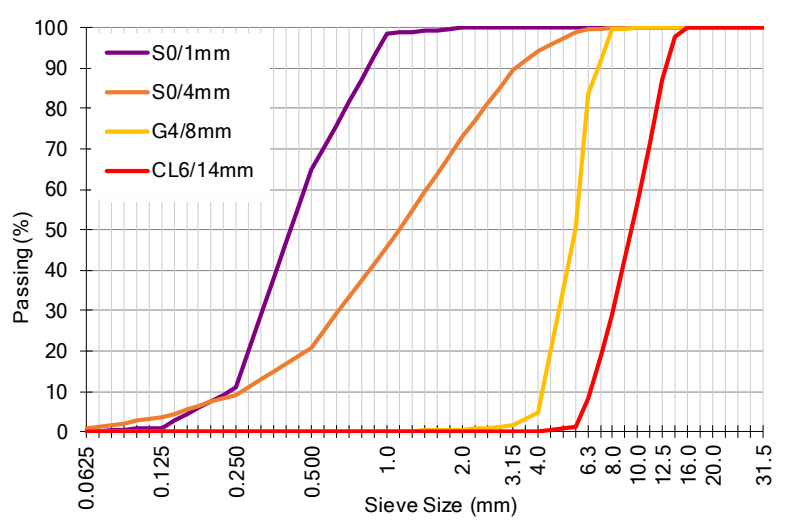

Fig. 1 Granulometric curves of the aggregates. to Portugal in its natural rocky form and finely ground in the laboratory using a planetary ball mill. The liquid part of the binder past was constituted by public water supply and MasterGlenium SKY 526 superplasticizer (MS). Table1 shows the chemical and physical characteristics and pozzolanic activity index of the hydraulic binders used in the formulation of the LCC herein studied.

\subsection{Concrete formulation}

The formulations of the LCC mixtures presented in this study were based on the methodology proposed by Lourenço et al. (2004), and further developed by Costa (2012), and using the Faury's reference curve because it generally confers better cohesion and workability to those types of concrete (Robalo et al. 2021). Known the properties of the constituent materials of concrete, several preliminary mixes were developed to calibrate some parameters of the composition and to optimize the binder paste of the reference mixtures. These mixtures had a standard binder dosage $\left(350 \mathrm{~kg} / \mathrm{m}^{3}\right)$ with a consistency class S2 (plastic consistency) and the effective dosage of cement ranged between 125 and $175 \mathrm{~kg} / \mathrm{m}^{3}$, in substitution regime by additions of limestone filler and fly ash. In the cement replacement process by additions, the limestone filler dosage was set at $100 \mathrm{~kg} / \mathrm{m}^{3}$, then the fly ash was added until the desired dosage for the binder powder was reached (Table 2). Despite being
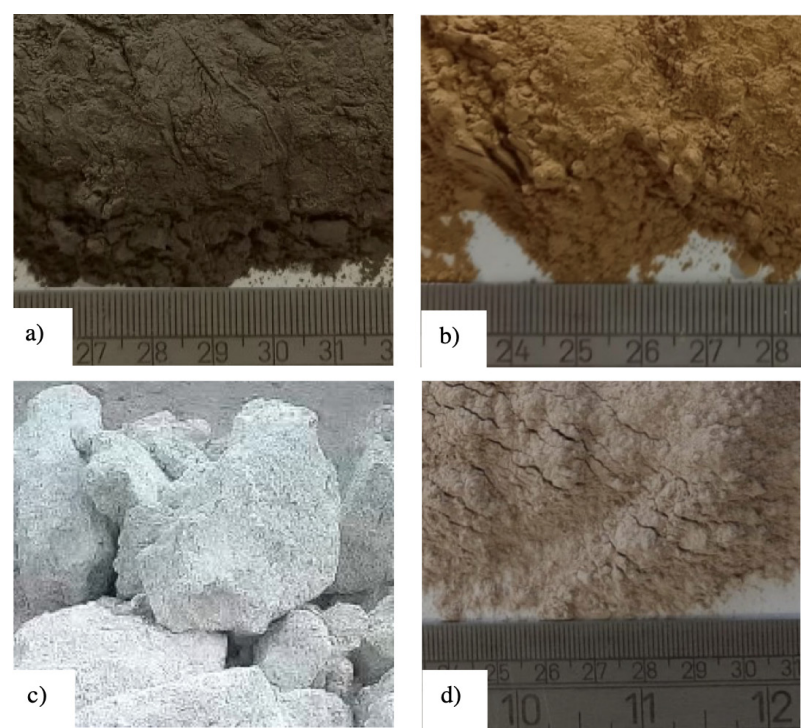

Fig. 2 Pozzolanic additions: a) fly ash; b) pozzolan from the Azores; c) Sample of raw pozzolana from Cape Verde, and d) ground pozzolan from Cape Verde. 
Table 2 Constituents proportion for $1 \mathrm{~m}^{3}, \mathrm{~W} / \mathrm{B}$ and W/C ratios.

\begin{tabular}{|c|c|c|c|c|c|c|c|}
\hline \multicolumn{2}{|c|}{ Materials $\left(\mathrm{kg} / \mathrm{m}^{3}\right)$} & $175 \mathrm{FA}$ & $175 \mathrm{PC}$ & $175 \mathrm{PA}$ & $125 \mathrm{FA}$ & $125 \mathrm{PC}$ & $125 \mathrm{PA}$ \\
\hline \multirow{5}{*}{ 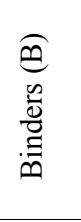 } & $\mathrm{C}$ & 175 & 175 & 175 & 125 & 125 & 125 \\
\hline & Limestone filler & 100 & 100 & 100 & 100 & 100 & 100 \\
\hline & FA & 75 & ---- & ---- & 125 & ---- & ---- \\
\hline & $\mathrm{PC}$ & ---- & 75 & ---- & ---- & 125 & ---- \\
\hline & PA & ---- & $\begin{array}{l}--- \\
\end{array}$ & 75 & ---- & ---- & 125 \\
\hline \multirow{6}{*}{ 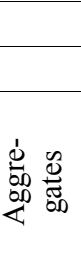 } & MS & 2.1 & 2.3 & 4.6 & 1.4 & 2.3 & 6.5 \\
\hline & Water (W) & 128 & 128 & 131 & 129 & 128 & 129 \\
\hline & $\mathrm{S} 0 / 1 \mathrm{~mm}$ & 181 & 179 & 179 & 185 & 182 & 183 \\
\hline & $\mathrm{S} 0 / 4 \mathrm{~mm}$ & 762 & 753 & 752 & 739 & 729 & 731 \\
\hline & $\mathrm{G} 4 / 8 \mathrm{~mm}$ & 92 & 91 & 91 & 92 & 92 & 91 \\
\hline & CL6/14mm & 894 & 890 & 884 & 898 & 894 & 887 \\
\hline \multicolumn{2}{|c|}{ Compactness } & 0.855 & 0.850 & 0.845 & 0.855 & 0.850 & 0.845 \\
\hline \multicolumn{2}{|r|}{$\mathrm{W} / \mathrm{B}$} & 0.366 & 0.365 & 0.373 & 0.368 & 0.365 & 0.368 \\
\hline \multicolumn{2}{|r|}{$\mathrm{W} / \mathrm{C}$} & 0.732 & 0.731 & 0.747 & 1.030 & 1.023 & 1.031 \\
\hline \multicolumn{2}{|c|}{$\mathrm{W} /(\mathrm{C}+0.4$.pozzolan $)$} & 0.624 & 0.624 & 0.639 & 0.737 & 0.731 & 0.737 \\
\hline
\end{tabular}

possible to produce LCC with a lower binder dosage (about $250 \mathrm{~kg} / \mathrm{m}^{3}$ ), previous research proved that option results in a lack of cohesion and plasticity in the fresh state, which is prejudicial for the workability (Robalo et al. 2021). So, to improve the workability, the limestone was added in that set proportion. Then, two mortar matrices were chosen, corresponding to the optimized formulation of the respective concretes, which were labelled as M125FA (mixture with $125 \mathrm{~kg} / \mathrm{m}^{3}$ of cement, $100 \mathrm{~kg} / \mathrm{m}^{3}$ of limestone filler, and $125 \mathrm{~kg} / \mathrm{m}^{3}$ of fly ash) and M175FA (mixture with $175 \mathrm{~kg} / \mathrm{m}^{3}$ of cement, 100 $\mathrm{kg} / \mathrm{m}^{3}$ of limestone filler, and $75 \mathrm{~kg} / \mathrm{m}^{3}$ of fly ash). The fly ash was replaced by the addition of natural pozzolans, resulting in the following mixtures: M125PC and M175PC - mixtures with pozzolans from Cape Verde; M125PA and M175PA - mixtures with pozzolans from the Azores. For those mixtures, the admixture dosage was experimentally adjusted to maximize the compactness with suitable workability and therefore to optimize the binder paste performance. Few adjustments to the maximum compactness were also performed for mixtures with pozzolans, compared to the mixtures with fly ash, due to the known effect of the round particles shape of the latter. The mortar matrices of the mixtures were characterized in terms of consistency, air content, compressive and flexural strengths, and the results were used for calibrating the formulation. It is quite visible in compactness adjustment, and mainly in superplasticizer dosage, that the natural pozzolans need higher water and superplasticizer, compared to fly ash addition, being that adjustment low for pozzolans of Cape Verde but huge for pozzolans of Azores. Subsequently, the aggregate proportion was optimized by adjusting the aggregate particle size curve to the Faury's reference curve. Finally, the several concretes corresponding to the developed mortar matrices were produced, namely 125FA, 175FA, 125PC, 175PC, 125PA, and 175PA, whose constituents proportioning and $\mathrm{W} / \mathrm{B}, \mathrm{W} / \mathrm{C}$ and
$\mathrm{W} /(\mathrm{C}+0.4$.pozzolan $))$ ratios are shown in Table 2.

\subsection{Experimental methods}

After the formulation, the production and characterization of LCC mixtures were performed. In fresh state, the matrices of their corresponding mortars were characterized in terms of consistency, by the flow table test, according to the EN 1015-3 (1998), density and air content by the pressure gauge method according to the EN 1015-6 (1998) and EN 1015-7 (1998), respectively.

The results were controlled through the comparison with the prediction considered in the formulation. The mortar matrices were also characterized in hardened state, with the purpose of calibrating the formulation, but the most rigorous study was performed on the corresponding concretes. Tests were carried out to evaluate not only their mechanical properties but also the durability performance. The compressive strength tests were performed using three cubic specimens of $150 \mathrm{~mm}$ edge, for each age considered $(7,28$, and 56 days) according to the EN 12390-3 (2009). The Young's modulus test was performed according to the LNEC E-397 specification (1993), using two prismatic specimens of $100 \times 100 \times 400 \mathrm{~mm}^{3}$ for each type of concrete. The three points flexural tests were performed until failure, in accordance with the EN 12390-5 (2009), on three prismatic specimens of $100 \times 100 \times 400 \mathrm{~mm}^{3}$, for each type of concrete. The splitting tests were carried out according to standard EN 12390-6 (2009) using three prismatic specimens of $100 \times 100 \times 200 \mathrm{~mm}^{3}$, also for each type of concrete.

Based on the results of mechanical properties and workability, two mixtures were selected for durability characterization: concrete 175FA, with fly ash addition; and concrete $175 \mathrm{PC}$, with natural pozzolan addition, from Cape Verde. Those concretes were characterized in terms of durability performance through the following tests: (i) water absorption through capillarity, according 
Table 3 Flow table, air content and density test results.

\begin{tabular}{|c|c|c|c|c|c|}
\hline \multirow{2}{*}{ Mixture } & \multirow{2}{*}{$\begin{array}{c}\text { Air content } \\
(\%)\end{array}$} & \multirow{2}{*}{$\begin{array}{c}\text { Slump flow } \\
\text { spread }(\mathrm{cm})\end{array}$} & Estimated & Measured & $\Delta$ \\
\cline { 4 - 6 } & 2.4 & 19.0 & 2.26 & 2.26 & $-0.2 \%$ \\
\hline M175FA & 3.1 & 16.5 & 2.24 & 2.24 & $0.0 \%$ \\
\hline M175PC & 3.1 & 16.5 & 2.24 & 2.24 & $0.1 \%$ \\
\hline M175PA & 2.1 & 21.0 & 2.24 & 2.26 & $1.0 \%$ \\
\hline M125FA & 3.5 & 17.0 & 2.21 & 2.21 & $0.0 \%$ \\
\hline M125PC & 3.2 & 15.5 & 2.21 & 2.22 & $0.2 \%$ \\
\hline M125PA & & & & & \\
\hline
\end{tabular}

to the LNEC E-393 (1993) specification, using three prismatic specimens of $100 \times 100 \times 200 \mathrm{~mm}^{3}$; (ii) accelerated carbonation test, carried out following the procedures defined in Nordtest NT Build 357 (Nordtest 1984), using three cylindrical samples with $100 \mathrm{~mm}$ in diameter and $50 \mathrm{~mm}$ thickness, for each considered exposure age $(7,28,56$ and 90 days), (iii) electrical resistivity, carried out on a cylindrical sample with $100 \mathrm{~mm}$ diameter and $200 \mathrm{~mm}$ height, according to AASHTO T358-15 (2015) and using certified equipment "Proceq Resipod" (Proceq 2017); (iv) non-steady-state chloride migration test: performed using three cylindrical specimens with $100 \mathrm{~mm}$ diameter and $50 \mathrm{~mm}$ thickness, for each age considered (28, 56 and 90 days), in accordance with the procedures of Nordtest NT Build 492 (Nordtest 1999), and using the PR-1100 cell of Proovéit system (Germann Instrument 2015); (v) chloride content on the concrete surface through the Volhard's method according to the standard EN 14629 (2007), using the second halves of the specimens from the non-steady-state chloride migration test, which were not sprayed with the silver nitrate solution. From these specimens, a portion of approximately $5 \mathrm{~mm}$ in depth or less was removed, depending on the results of the chloride penetration depth, parallel to the surface that was exposed to the chloride solution.

After carrying out the laboratory tests, the performance related to the corrosion resistance of the steel reinforcements, namely, the carbonation resistance and the penetration of chlorides, were used to assess the service life of the reinforced concrete structures produced with 175PC and 175FA. This information is important to be considered on the sustainability evaluation of these concretes.

\section{Results and discussion}

\subsection{Properties of fresh concrete}

The results of the flow table test and air content of the mortar matrices of the several concretes, which were named with $\mathrm{M}$ plus the reference of the corresponding concrete, are shown in Table 3. The results estimated and measured concerning density are also presented, and the deviations $(\Delta)$ between them were less than $1 \%$, proving the efficiency of the used methodology to formulate this type of matrices. It is concluded that fly ash gives better workability than the used pozzolanic additions, even in cases with lower water and superplasti- cizer contents. This result is due to the spherical shape of its particles. On the other hand, it is found that to meet the workability required in mixtures with natural pozzolans, a higher dosage of superplasticizer was needed (Table 2). Comparing the mixtures with pozzolanic additions, those with Azores pozzolan required not only higher demand of superplasticizer but also higher water dosage, resulting in a lower compactness.

\subsection{Mechanical Properties}

\subsubsection{Compressive strength}

Figure 3 present the evolution of the average compressive strength, $\mathrm{f}_{\mathrm{cm}}$, with the age $(\mathrm{t})$, for all produced concretes, and the curves corresponding to the predictions determined using Equation (1).

$$
\mathrm{f}_{\mathrm{cm}}(t)=\exp \left(\mathrm{s}_{\mathrm{c}} \times(1-\sqrt{28 / t})\right) \times \mathrm{f}_{\mathrm{cm} 28}
$$

where the parameter $s_{c}$ is equal to 0.2 for concrete adjusted with the " $R$ " type curve (rapid hardening curve), 0.25 for concrete adjusted with the " $\mathrm{N}$ " type curve (normal hardening curve), and 0.38 for concrete adjusted with the "S" type curve (slow hardening curve), according to Eurocode 2 (EC2) (EN 1992-1-1 2010). The experimental results of mixtures with a higher rate of cement replacement by additions (64\%), in particular with higher pozzolanic addition fit better with the type "S" curve. While mixtures with a lower cement replacement rate by additions (50\%), only $175 \mathrm{PA}$ concrete presented an adequate fit with the type "N" curve. Other concretes (175PC and 175FA) do not fit with any curve proposed by EC2. The hardening curve considering $\mathrm{s}_{\mathrm{c}}=$ 0.30 is the closest to the experimental values obtained for these concretes, a hardening between $\mathrm{N}$ and $\mathrm{S}$ curves, this is due to the lower pozzolanic content. The use of additions has a certain limitation in construction industry since it presents a slower curing curve at young ages (Cost and Aci 2011). However, the results show that is possible to produce concrete with a low cement dosage, optimizing its constituents, simultaneously mitigating that limitation, depending on the binder proportions. Figure 3 shows a hardening evolution similar to the curve type $\mathrm{N}$ or close to that (with $\mathrm{s}_{\mathrm{c}}=0.3$ ).

Comparing the average compressive strength, $\mathrm{f}_{\mathrm{cm}}$, measured at 7, 28, and 56 days (Fig. 4), it is noted that this parameter increases with the increase of cement dosage and, consequently, with the decrease of W/C ratio, as expected (Table 2). It is also evident that 
among concretes with the same cement content, those that include the addition of Cape Verde pozzolan (PC) have higher compressive strength. Being a pozzolanic material, that do not require a very high superplasticizer dosage, has the potential to develop strengths up to $7 \%$ greater than those obtained with fly ash addition.

\subsubsection{Young's modulus}

The average Young's modulus, $\mathrm{E}_{\mathrm{cm}}$, measured at 28 days are presented in Fig. 5. It is confirmed, similarly to compressive strength, that Young's modulus also increases with the cement dosage increase and with the W/C ratio decrease (see Table 2). The replacement of fly ash by Cape Verde or Azores pozzolan additions causes a reduction of Young's modulus, except for 175PC, where the replacement of fly ash by Cape Verde pozzolan does not produce significant variation. In the remaining mixtures, that reduction increases with the replacement by pozzolans, achieving a maximum of $14 \%$, in the Azores pozzolan concrete (125PA). This can be explained essentially by the increase in air and water content in the binder matrix, caused by the workability loss. It is highly plausible that the stiffness of the pasteaggregate transition zone also plays a key role in this analysis.

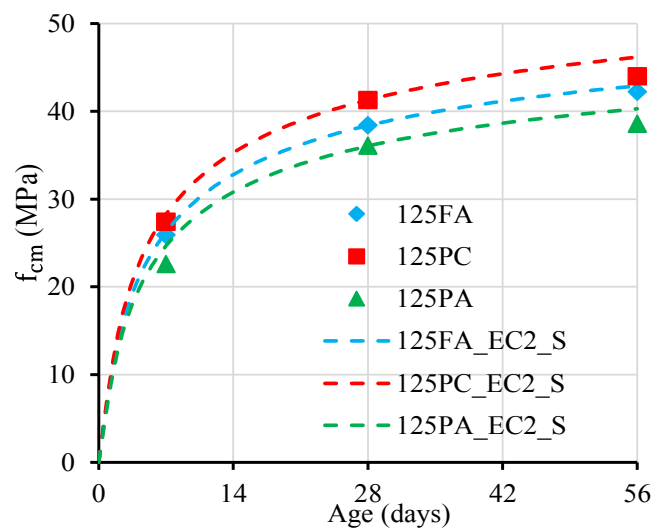

Fig. 3 Evolution of the compressive strength with age of concrete with cement content of $125 \mathrm{~kg} / \mathrm{m}^{3}$ (left) and of $175 \mathrm{~kg} / \mathrm{m}^{3}$ (right).

\subsubsection{Tensile strength}

Figure 6 shows the average tensile strength, by splitting $\left(f_{c t m, s}\right)$ and by flexural $\left(f_{c t m, f}\right)$ tests of the studied conlower than the flexural tensile strength, as expected. It is also noted that the increase of the cement substitution by fly ash increases the tensile strength of concrete. Regarding the splitting strength, the replacement of fly ash by pozzolans from Cape Verde and Azores, in the mixture with $175 \mathrm{~kg}$ of cement, results in strength increases of approximately $13 \%$ and $15 \%$, respectively, while in the mixtures with only $125 \mathrm{~kg}$ of cement, there is a strength loss of $14 \%$ for both. This shows that if those pozzolans increase above to a certain dosage, the tensile strength tends to decrease, in comparison to mixtures with fly ash. The results of flexural tensile strength confirm that the replacement of fly ash by pozzolans causes a strength decrease in certain quantities. The exception was the 175PA, where the flexural tensile strength is about $19 \%$ higher than the corresponding concrete with fly ash addition. The maximum loss observed was $22 \%$ and occurred on concrete with a higher dosage of Cape Verde pozzolan (125PC).

In general, the characterization of tensile strengths showed a significant variability and that the fineness of the pozzolans, higher in the Azores than in Cape Verde, apparently has a higher influence on the tensile strength

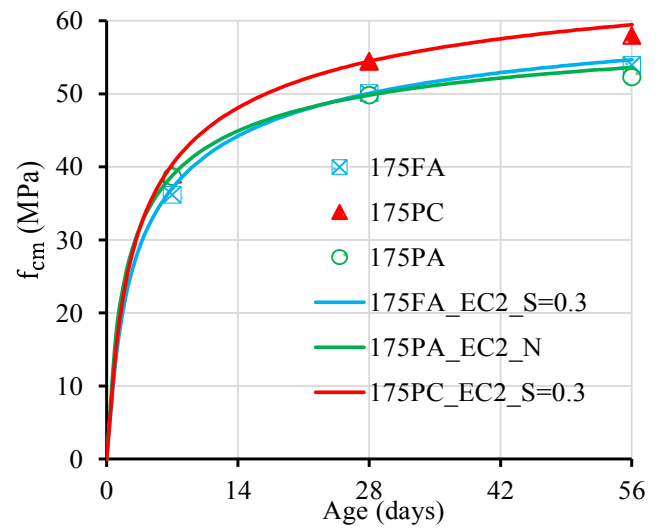
cretes, and can be seen that the splitting strength is

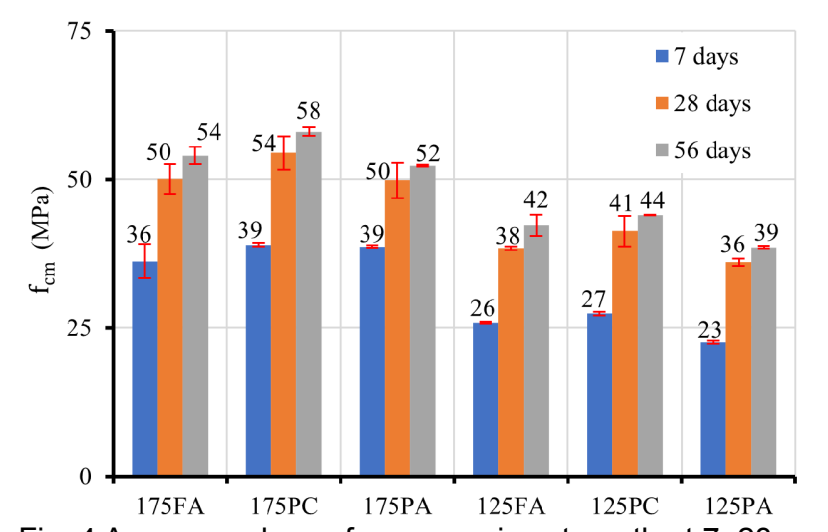

Fig. 4 Average values of compressive strength at 7,28 and 56 days.

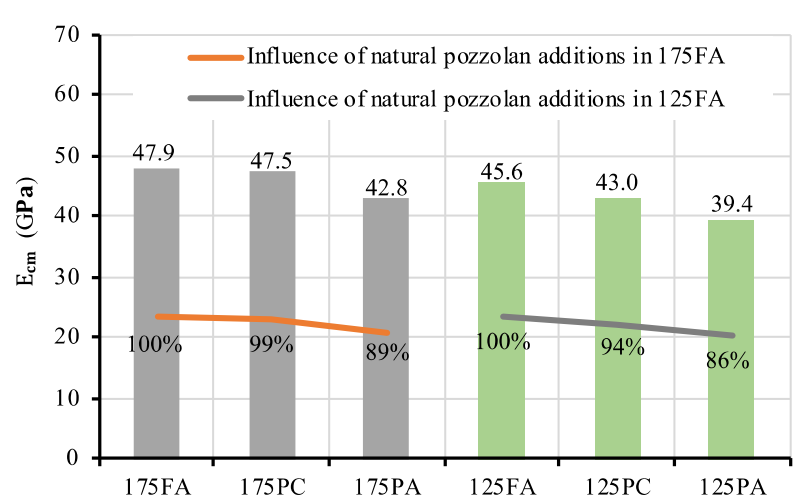

Fig. 5 Average Young's modulus at 28 days. 
than in flexural strength. It is further emphasized that the Cape Verde pozzolan has the potential to be ground to finer particle size, which is expected to significantly increase its performance in terms of tensile strengths.

\subsection{Durability properties}

\subsubsection{Water absorption through capillarity}

Capillarity water absorption is one of the main parameters for controlling the transport of aggressive agents and, consequently, the durability of concrete, because is related to the liquid penetration into the material. Figure 7 presents the average capillary height at the instant $t_{i}$, $\mathrm{h}\left(\mathrm{t}_{\mathrm{i}}\right)$, in $\mathrm{mm}$, and the average capillary absorption values at the instant $\mathrm{t}_{\mathrm{i}}, \mathrm{S}_{\mathrm{a}}\left(\mathrm{t}_{\mathrm{i}}\right)$, in $\mathrm{mg} / \mathrm{mm}^{2}$. According to these values, significant improvements can be noted when fly ash is replaced by pozzolan from Cape Verde. Comparing the 175FA and 175PC concrete it is observed that the second has lower capillarity absorption, that difference varies between $36 \%$ and $23 \%$, decreasing with the duration of the test. Both concrete show a clear and a more pronounced capillary absorption in the initial stages. Analyzing in detail the two graphs, it appears that 175FA presents in all sections a slope slightly higher than that of the 175PC, which allows to state that the first has a porous network more favorable to water penetration. According to Coutinho (2005), the slope variation of the relation capillary ascension vs. time gives information about the opening and the connection of the porous network in the matrix, since initially there is a rapid saturation of the accessible pores and then a slow saturation of the isolated macropores.

Figure 8 shows the relation between the average values of capillary absorption $\mathrm{S}_{\mathrm{a}}$, in $\mathrm{mg} / \mathrm{mm}^{2}$, and the square root of time, obtained for each mixture, as well as the trend line corresponding to the best fit of the points. The slope of those lines represents the capillary absorption coefficient. It is also presented the line corresponding to the high-quality concrete, $\mathrm{S}_{\mathrm{a}}=0.1$ $\mathrm{mg} /\left(\mathrm{mm}^{2} \cdot \mathrm{min}^{1 / 2}\right)$, according to Browne (1991). The lines of both concrete present a correlation coefficient greater than 0.95 and can be classified as high-quality concrete because the results are clearly below that limit. It is also noted that the capillary absorption coefficient of concrete 175FA is slightly higher than that of concrete $175 \mathrm{PC}$, proving that the latter has a lower porous matrix than the former.

\subsubsection{Carbonation}

In Fig. 9 is possible to observe the carbonation evolution at 7, 28, 56, and 90 days of exposure. At 7 days the carbonation in $175 \mathrm{PC}$ was null, while in $175 \mathrm{FA}$, the beginning of carbonation is slightly observed but almost imperceptible. In the remaining periods of exposure, the carbonation depth is much more notable. Figure $\mathbf{1 0}$ plots graphically the average carbonation depth, $\mathrm{C}_{\mathrm{d}}$, in $\mathrm{mm}$ vs. square root of the exposure time for each mixture, as well as the trend line corresponding to the best fit of points. The slope of those lines represents the car-
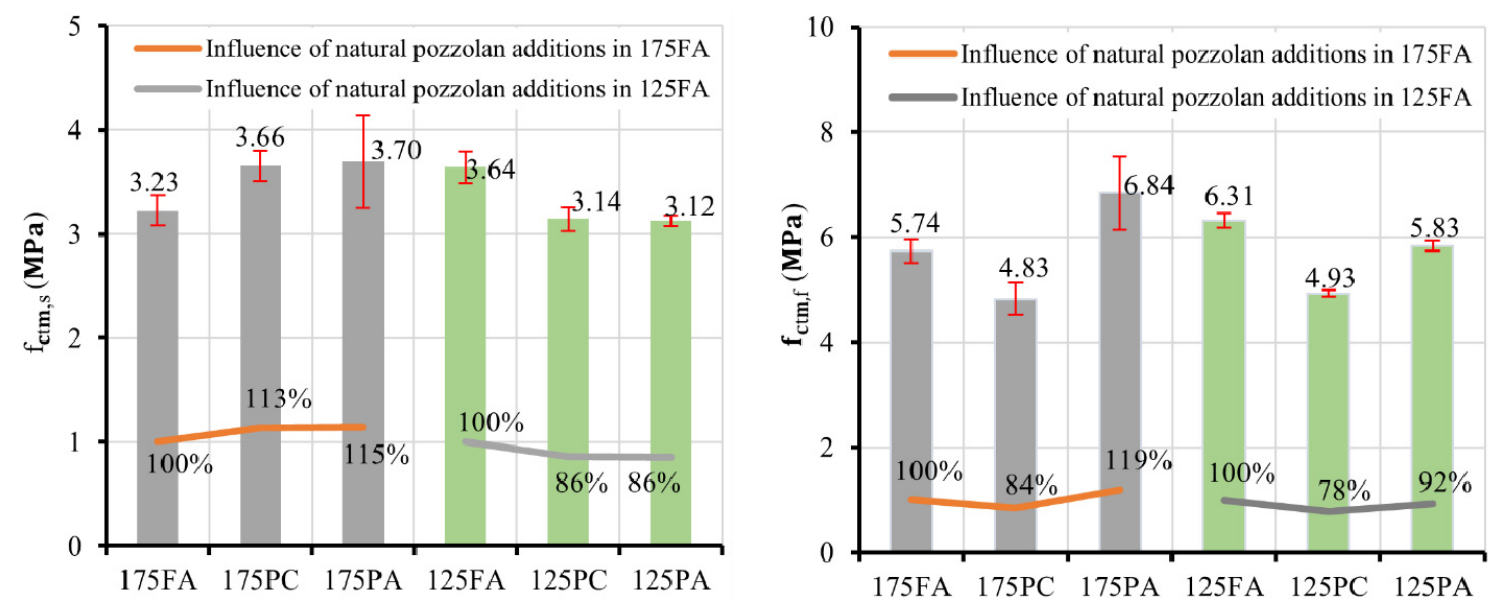

Fig. 6 Tensile strengths of concretes: splitting tensile strength (left); flexural strength (right).
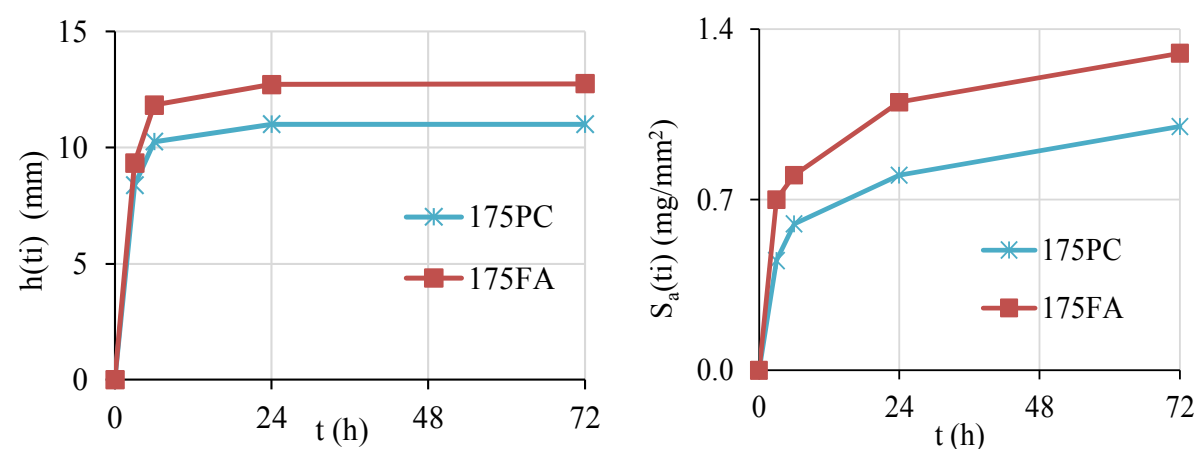

Fig. 7 Results of capillary water absorption: capillary ascension height (left); capillary absorption, Sa (right). 
bonation coefficient. Both concrete (175FA and 175PC) present a correlation coefficient greater than 0.99 and the carbonation velocity is practically constant over the analyzed range of time, contrary to what was expected. Typically, the velocity is higher in the first days and tends to be slower overtime, because after carbonation begun the resulting products occupy the voids in the porous matrix and make more difficult the diffusion of the carbon dioxide into concrete, decreasing the carbonation rate. The carbonation coefficient of 175FA is about $2.24 \mathrm{~mm}$.days ${ }^{1 / 2}$, while the $175 \mathrm{PC}$ is around 1.94 mm.days ${ }^{1 / 2}$, which means that the carbonation rate of the former is $15.5 \%$ higher than the latter. This tendency was verified in the capillary absorption test and may be associated with the same reason: the matrix structure seems more porous in fly ash concrete and, consequently, the diffusion of the carbon dioxide through the concrete is greater.

\subsubsection{Electrical resistivity}

The electrical resistivity test of concrete gives an indication of its permeability and, therefore, can be related, qualitatively, with the penetration rate of the chloride ion into the concrete. A higher resistivity value implies a lower chloride penetration rate into the concrete. Comparing the electrical resistivity of $175 \mathrm{FA}$ and $175 \mathrm{PC}$ concretes, expressed in $\mathrm{k} \Omega \mathrm{cm}$, measured at $28,30,56$, 90, and 120 days (Fig. 11) with the limits presented in AASHTO T358-15 (2015), it is verified that those two concretes show a very low chloride penetration rate, especially at advanced ages, since they have resistivity

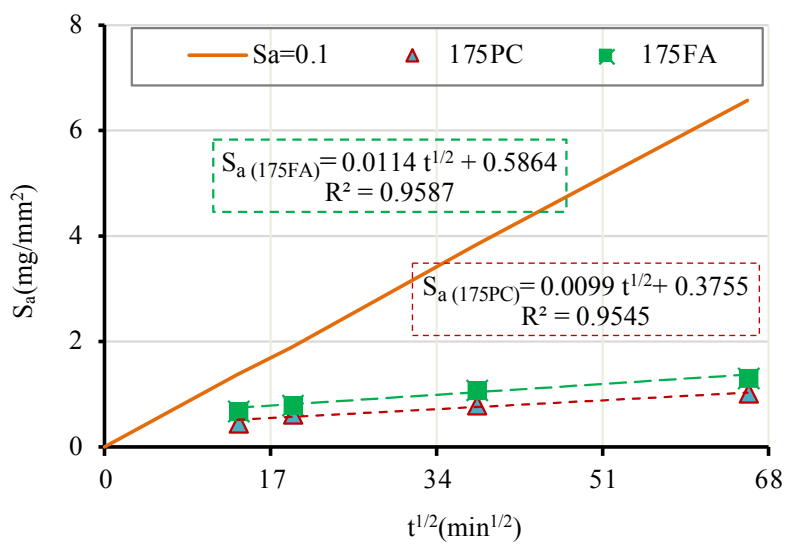

Fig. 8 Capillary absorption vs. square root of time.
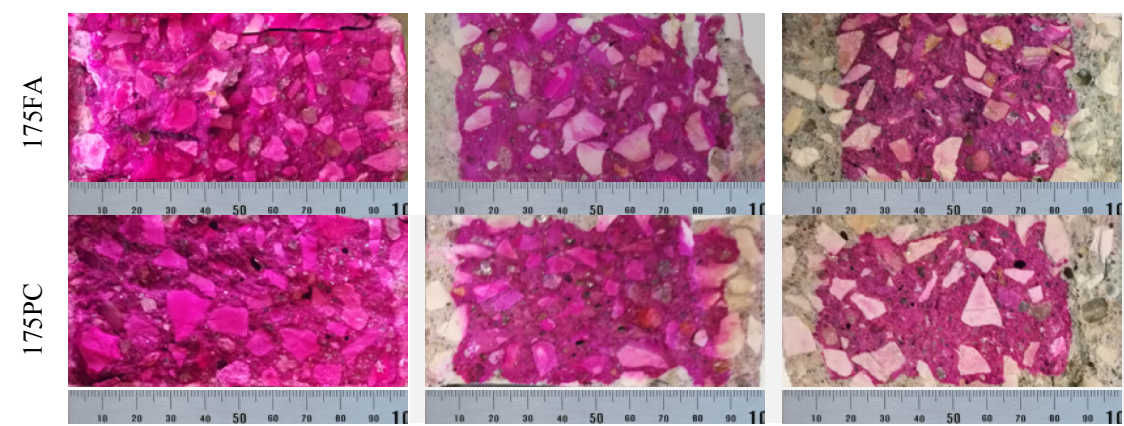

values of $51.3 \mathrm{k} \Omega \mathrm{cm}$ in $175 \mathrm{PC}$ and $61.0 \mathrm{k} \Omega \mathrm{cm}$ in 175FA, which is between the limits 37 and $254 \mathrm{k} \Omega \mathrm{cm}$ defined for that classification. Figure 11 also shows that electrical resistivity increases with age for both concrete. The average value of electrical resistivity of the 175PC mixture at 28 days is significantly higher relative to $175 \mathrm{FA}$, about $45 \%$. However, after 56 days, this difference significantly decreased, inverting the relative position at 90 days. At 90 days the resistivity of 175FA is $8 \%$ higher than the $175 \mathrm{PC}$ and at 120 days the difference is doubled approximately, being around $16 \%$. This fact may be associated with the development of an improved microstructure of concrete with fly ash at a longer curing period.

\subsubsection{Chloride migration coefficient}

After the concrete specimens being subject to a chloride

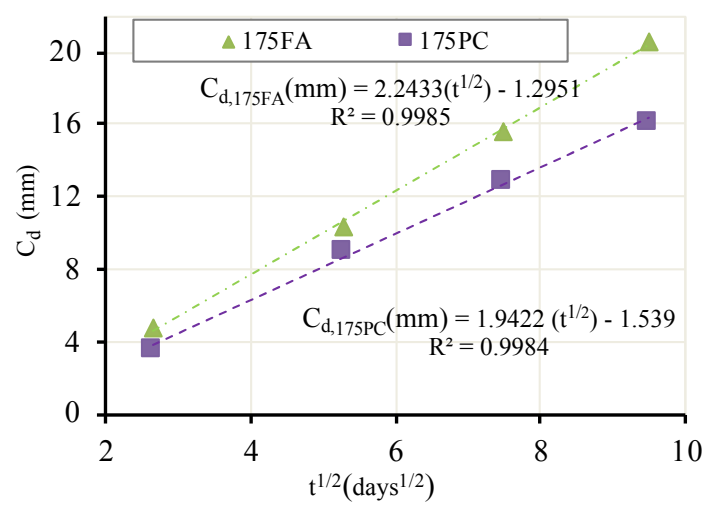

Fig. 10 Carbonation depth vs square root of time.

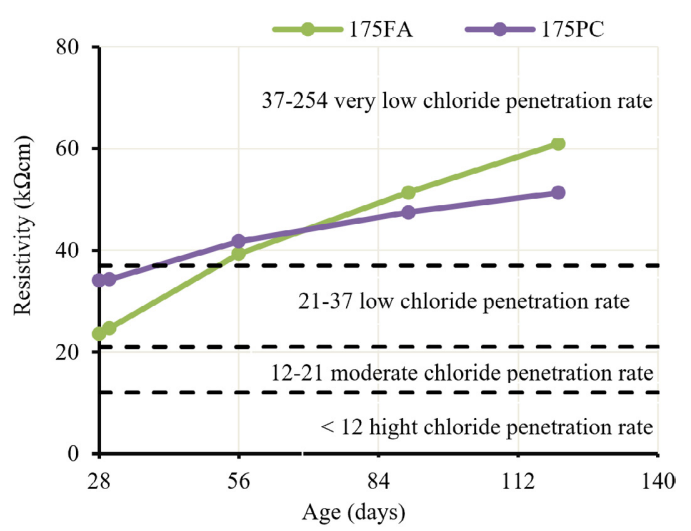

Fig. 11 Variation of electrical resistivity with age.

Fig. 9 Carbonation depth on concrete specimens at $7,28,56$, and 90 days of exposure to $\mathrm{CO}_{2}$. 
migration according to the procedures of Nordtest NT Build 492 (Nordtest 1999), the penetration depth was measured. The silver color of the silver nitrate reaction identifies that chloride penetration depth, $x_{d}$ (Fig. 12). The average value of the non-steady-state chloride migration coefficient, $\mathrm{D}_{\mathrm{nssm}}$, was calculated using Equation (2).

$$
D_{\text {nssm }}=\frac{0.0239 \cdot(273+T) \cdot L}{(U-2) \cdot t} \cdot\left(x_{d}-0.0238 \cdot \sqrt{\frac{(273+T) \cdot L \cdot x_{d}}{U-2}}\right)(2)
$$

where $\mathrm{U}$ is the absolute value of the applied voltage, $\mathrm{V}$; $\mathrm{T}$ is the average value of the initial and final temperatures in the anodic solution, ${ }^{\circ} \mathrm{C}$; $\mathrm{L}$ is the thickness of the specimen, $\mathrm{mm} ; \mathrm{x}_{\mathrm{d}}$ is the average value of the penetration depths, $\mathrm{mm}$; and $\mathrm{t}$ is the test duration in hours. The results show a decrease of the chloride migration coefficient with age in both concretes, as was already expected, however with different trends, mainly in concrete with pozzolana from Cape Verde (Fig. 13). In concrete with fly ash, 175FA, the chloride migration coefficient decreases about $43 \%$ between 28 and 56 days of age, while drops only $17 \%$ between 56 and 90 days of age, showing a tendency for the coefficient stabilization with the age. This proves that the pozzolanic reactions of fly ash occur at later ages, delaying the formation of additional C-S-H and consequent refinement of the concrete microstructure. The concrete with pozzolana from Cape Verde, 175PC, has a different trend since the coef-

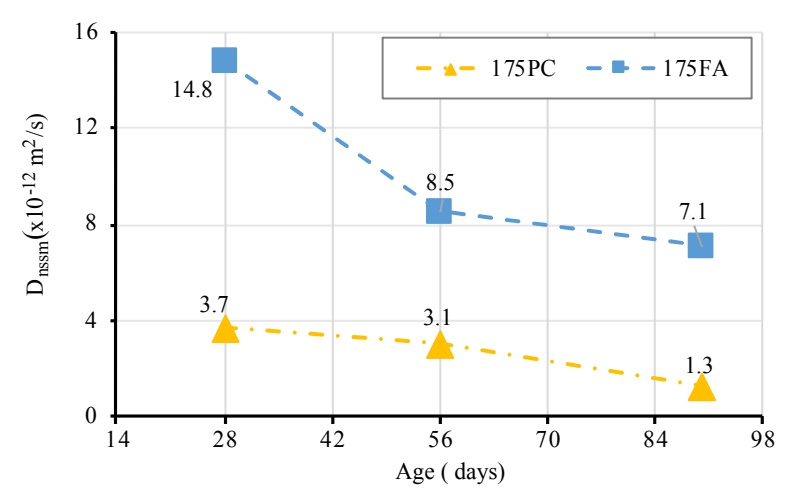

Fig. 13 Variation of non-steady-state chloride migration coefficient with the age of concrete. ficient decreases only $17 \%$ between 28 and 56 days and $60 \%$ between 56 and 90 days. This trend seems to indicate that the pozzolanic activity of 175PC starts earlier than that of 175FA concrete and lasts longer, which is probably related with the higher LOI value of pozzolan comparing to that of fly ash. This is contrary to the initial expectations, considering only the pozzolanic activity index at 28 days, indicated in Table 1, because the fly ash has a higher reactivity index than pozzolans. However, those results must be associated with other factors, since the effect of SCM on the mechanical performance of matrices with reduced cement content and high compactness is promoted not only by pozzolanic reactivity but also by filler and packing effects (Robalo et al. 2021).

On the other hand, the diffusion coefficient of 175PC is 4 to 6 times lower than that of 175FA, depending on age, meaning that the diffusion of chlorides through the $175 \mathrm{PC}$ is slower. However, the opposite was expected, since the incorporation of fly ash in concrete causes an effective increase of C3A, which is attributed, according to several authors (Dinakar et al. 2008; Thomas et al. 2012), to the presence of alumina in large quantities in its composition (Table 1). This increase of C3A associated with a possible increase of $\mathrm{C}-\mathrm{S}-\mathrm{H}$, resulting from pozzolanic reactions, leads to a greater chloride fixation capacity, reducing the chloride diffusion coefficient (Dinakar et al. 2008; Thomas et al. 2012). However, the results obtained did not follow this explanation, the chemical characterization of the binders presented in Table 1 shows that the fly ash has higher alumina content than pozzolan from Cape Verde and the corresponding concrete also has a higher diffusion coefficient.

The results lead to the conclusion that the $175 \mathrm{PC}$ has a less porous microstructure, also proven in capillary absorption and carbonation tests, probably due to higher effect of pozzolanic reaction that starts earlier and is prolonged in time. Furthermore, taking into account the values obtained after 56 days, and using the Gjorv classification (Gjorv 1996), the 175PC fits into the "very high-quality concrete" since it presents a $\mathrm{D}_{\text {nssm }}$ between 2.5 and $5 \times 10^{-12} \mathrm{~m}^{2} / \mathrm{s}$, while $175 \mathrm{FA}$ is classified as a "high-quality concrete", because the $\mathrm{D}_{\text {nssm }}$ is between 5 and $10 \times 10^{-12} \mathrm{~m}^{2} / \mathrm{s}$.
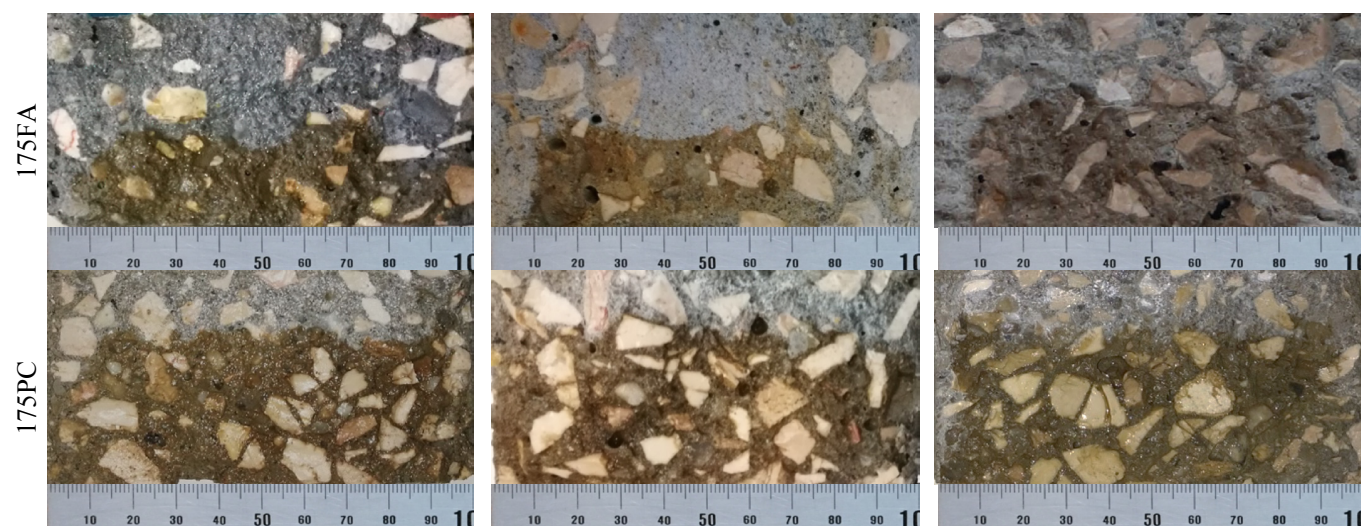

Fig. 12 Penetration depth, $x_{d}$, on concrete specimens at 28,56 and 90 days. 
Comparing the results obtained in the non-steadystate chloride migration test with those of resistivity (Figs. 11 and 13), a contradiction is noted, mainly after 56 days of concrete age. According to the resistivity results, 175FA concrete would present, at the age of 90 days, greater resistance to chloride penetration than $175 \mathrm{PC}$ concrete, therefore, contrary to the conclusion achieved in the non-steady-state chloride migration test. The linear correlation coefficient, $\mathrm{R}^{2}$, between the chloride diffusion coefficient and the electrical resistivity in the $175 \mathrm{FA}$ concrete is 0.93 , being only 0.87 in the 175PC concrete (Fig. 14). The differences between the results in these two methods can point out different influences in the microstructure and in the ionic composition of the paste. The influence of cure and the preconditioning of specimens on both tests can also have a key role on the interpretation of these results. The method to assess the resistance to chloride penetration using the electrical resistivity test is faster than the accelerated chloride migration test but has some disadvantages, namely, the final result is a qualitative classification. The difference in potential applied, as well as other parameters involved in this test, was the same that is used on conventional concrete specimens, with a normal binder dosage, it may not be adequate use the same potential difference for LCC. Considering all these variables and although is more time-consuming, it is more prudent to use a method based on migration to assess the penetration of chlorides in the studied concrete, it

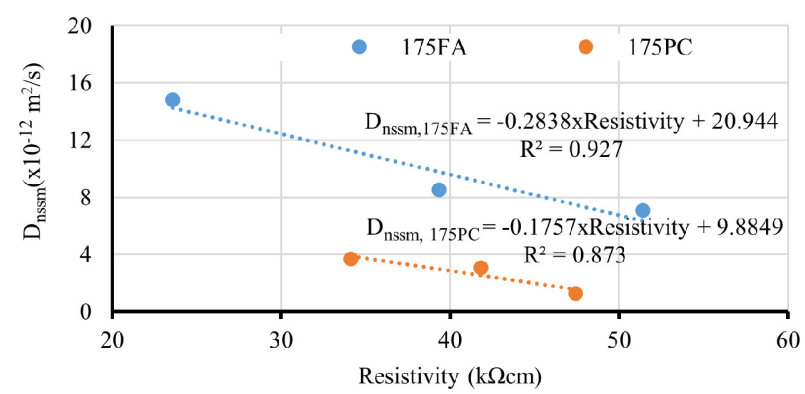

Fig. 14 Correlation between the chloride diffusion coefficient and the electrical resistivity.

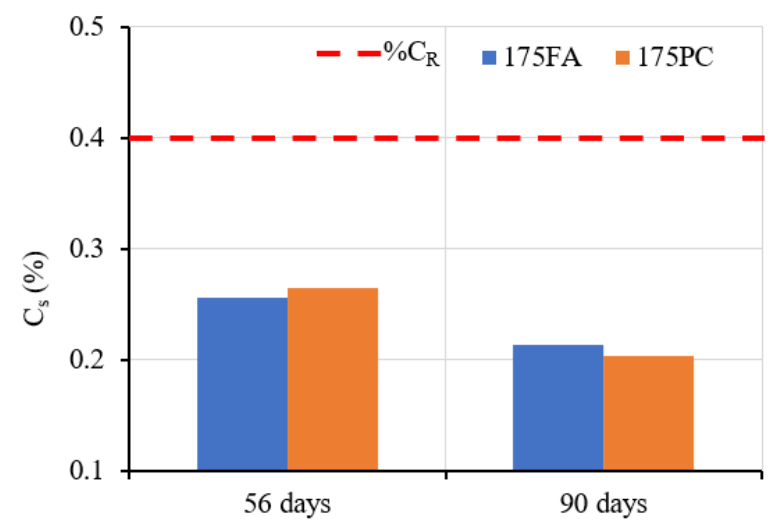

Fig. 15 Chloride content at the concrete surface 175PC and $175 \mathrm{FA}$ at 56 and 90 days of age and critical chloride content. represents better the concrete behaviour exposed to this type of environment.

\subsubsection{Chloride content at the concrete surface}

The determination of surface chloride content $\left(\mathrm{C}_{\mathrm{s}}\right)$ was also performed to evaluate the risk of steel corrosion of structures made with $175 \mathrm{FA}$ and $175 \mathrm{PC}$ concretes. This risk is evaluated based on the condition that there is only aggressive action on the steel reinforcement if $\mathrm{C}_{\mathrm{S}}$ is superior to a certain critical value (LNEC E-465 2007), $\left(\% C_{R}\right)$. Figure 15 shows the average values of $C_{s}$ per mass of cement and type II addition, at 56 and 90 days of age. These values were measured, initially, in concrete mass using Equation (3) and later relatively to the mass of cement and type II addition using Equation (4). After, those values were compared with the critical value of EN 206-1 (2007). In $100 \mathrm{~g}$ of 175 FA concrete mass there is $10.37 \mathrm{~g}$ of cement plus fly ash and $10.44 \mathrm{~g}$ of cement plus pozzolan from Cape Verde in the case of $175 \mathrm{PC}$ concrete.

$$
\mathrm{CC}=3.545 \times \mathrm{f}_{\mathrm{AgNO}_{3}} \frac{\mathrm{V}_{\mathrm{NH} S \mathrm{CN}}^{\text {blanc }}-\mathrm{V}_{\mathrm{NH} \mathrm{SCN}}^{\text {concrete }}}{\mathrm{m}_{\text {concrete }}}
$$

where $\mathrm{f}_{\mathrm{AgNO}_{3}}$ is the molarity of silver nitrate solution, $\mathrm{V}_{\mathrm{NH} S \mathrm{CCN}}^{\mathrm{blanc}}$ is the volume of the ammonium thiocyanate solution used in the blank titration $(\mathrm{ml}), \mathrm{V}_{\mathrm{NH} S C \mathrm{~N}}^{\text {concete }}$ is the volume of the ammonium thiocyanate solution used in the titration ( $\mathrm{ml})$, and $\mathrm{m}_{\text {concrete }}$ is the mass of the concrete sample $(\mathrm{g})$.

$$
\mathrm{CC}_{\mathrm{m}_{\text {cement addition type II }}}=\frac{\mathrm{CC}}{\mathrm{m}_{\text {cement type II addition }}} \times 100
$$

The results show that the type of addition used in LCC has no significant influence on the chloride content of the surface because both concrete present similar $\mathrm{C}_{\mathrm{s}}$ values, both at 56 and at 90 days of age. A similar conclusion was drawn by Costa and Aplleton (1999) in a different research. It is also noted that the chloride contents on the surface show a decrease over the age since the values of concrete with 90 days are $23 \%$ lower than those with 56 days. These results must be associated with a reduction and refinement of the porous concrete structure. Comparing these values with the critical chloride content $\left(\% \mathrm{C}_{\mathrm{R}}\right), 0.4 \%$ according to $\mathrm{EN} 206-1$ (2007), the studied concretes have lower chloride content values. Meaning that there is no risk of corrosion in the analyzed periods after being exposed to chloride, according to the test described in LNEC E-463 (2004), which is not surprising taking into account the short period of exposure.

\subsection{Service life of structures and minimum concrete cover analysis}

Based on the results obtained in the durability tests, using the Tuutti model for reinforced concrete degradation caused by steel corrosion and the recommendations described in LNEC E465 (2007), the following parameters 
were determined: (i) the minimum concrete cover, $\mathrm{c}_{\text {min,dur }}$, required to assure a proper protection against reinforcement corrosion during the intended service life of structures exposed to environmental conditions $\mathrm{XC}$ (corrosion induced by carbonation) and XS (corrosion induced by chlorides present in seawater) (EN 206-1 2007); (ii) prediction of the service life of reinforced concrete structures using the developed concretes and the standard covers when exposed to environmental conditions XC and XS. For this study, two types of structures were analyzed: (i) current structures with an intended service life $\left(t_{\mathrm{g}}\right)$ equal to 50-year-old, with a reliability class $\mathrm{RC} 2$, which corresponds to a safety factor $\gamma$ equal to 2.3; (ii) special structures with a tg equal to 100 -year-old, with a reliability class $\mathrm{RC} 3$, which corresponds to a safety factor $\gamma$ equal to 2.8 .

\subsubsection{Determination of the minimum cover to resist carbonation-induced corrosion}

The calculation of the minimum cover necessary to guarantee the proper resistance against steel corrosion under the environmental exposures classes XC involves essentially the determination of three parameters: i) the carbonation resistance, $\mathrm{R}_{\mathrm{C} 65}$, of the studied concretes, $175 \mathrm{PC}$ and $175 \mathrm{FA}$; ii) the design period of initiation, $\mathrm{t}_{\mathrm{ic}}$; and iii) the carbonation depth for several environmental exposure classes.

Based on the carbonation depth values, $\mathrm{C}_{\mathrm{di}}$, experimentally determined (Fig. 10) at 28, 56, and 90 days of exposure to carbon dioxide, with a concentration, $\mathrm{C}_{\mathrm{acel}}$, approximately equal to $90 \times 10^{-3} \mathrm{~kg} / \mathrm{m}^{3}$, the carbonation resistance, $\mathrm{R}_{\mathrm{C} 65}\left(\mathrm{~kg} . \mathrm{year} / \mathrm{m}^{5}\right)$, was determined using the Equation (5). The results are shown in Table 4.

$$
\mathrm{R}_{\mathrm{C} 65}=\frac{2 \times \mathrm{C}_{\mathrm{acel}} \times \mathrm{t}_{\mathrm{i}}}{\mathrm{C}_{\mathrm{di}}^{2}}
$$

The design period of initiation, $t_{i c}$, was determined using Equation (6).
Table 4 Carbonation resistance.

\begin{tabular}{|c|c|c|c|c|}
\cline { 2 - 5 } \multicolumn{1}{c|}{} & \multicolumn{4}{c|}{$\mathrm{R}_{\mathrm{C} 65}\left(\mathrm{~kg}\right.$. year $\left./ \mathrm{m}^{5}\right)$} \\
\hline Concrete & 28 days & 56 days & 90 days & Average \\
\hline $175 \mathrm{PC}$ & 172.1 & 166.6 & 173.4 & 170.7 \\
\hline $175 \mathrm{FA}$ & 129.3 & 113.1 & 105.6 & 116.0 \\
\hline
\end{tabular}

Table 5 Minimum propagation period and the initiation period due to carbonation.

\begin{tabular}{|c|c|c|c|c|c|}
\hline & & $\mathrm{XC} 2$ & $\mathrm{XC} 3$ & $\begin{array}{c}\text { XC4 (dry } \\
\text { regime) }\end{array}$ & $\begin{array}{l}\mathrm{XC} 4 \text { (wet } \\
\text { regime) }\end{array}$ \\
\hline \multirow{2}{*}{$\begin{array}{c}\mathrm{t}_{\mathrm{g}}=50 \\
\text { years } \\
(\mathrm{RC} 2)\end{array}$} & $\begin{array}{c}t_{\mathrm{p}} \\
\text { (years) }\end{array}$ & 10 & 45 & 15 & 5 \\
\hline & $\begin{array}{c}t_{i c} \\
\text { (years) }\end{array}$ & 92 & 12 & 80 & 105 \\
\hline \multirow{2}{*}{$\begin{array}{c}t_{g}=100 \\
\text { years } \\
(\mathrm{RC} 3)\end{array}$} & $\begin{array}{c}t_{\mathrm{p}} \\
\text { (years) }\end{array}$ & 20 & 90 & 20 & 10 \\
\hline & $\begin{array}{c}t_{i c} \\
\text { (years) }\end{array}$ & 224 & 28 & 224 & 252 \\
\hline
\end{tabular}

$$
\mathrm{t}_{\mathrm{ic}}=\gamma\left(\mathrm{t}_{\mathrm{g}}-\mathrm{t}_{\mathrm{p}}\right)
$$

The propagation time, $t_{p}$, is determined using a model based on the intensity of the electrochemical. In Table 5 is shown the values of $t_{p}$ and $t_{i c}$ calculated accordingly to the specification of LNEC E-465 (2007). The minimum cover required to assure protection of the reinforcement against corrosion, $\mathrm{c}_{\mathrm{min}, \mathrm{dur}}$, is considered equal to the carbonation depth, $\mathrm{C}_{\mathrm{di}}$, determined for a time equal to $\mathrm{t}_{\mathrm{ic}}$. The $\mathrm{c}_{\text {min,dur }}$ can be determined in two ways, directly using Equation (7) or by the intersection between the $\mathrm{R}_{\mathrm{C} 65}$ value experimentally determined, for each concrete, with the curves corresponding to the $\mathrm{R}_{\mathrm{C} 65}$ required for the several exposure classes XC (Figs. 16 and 17).

$$
\mathrm{C}_{\mathrm{di}}=\sqrt{\frac{2 \times 0.0007 \times \mathrm{t}_{\mathrm{iC}}}{\mathrm{R}_{\mathrm{C} 65}}} \times \sqrt{\mathrm{k}_{0} \times \mathrm{k}_{1} \times \mathrm{k}_{2}} \times\left(\frac{\mathrm{t}_{0}}{\mathrm{t}_{\mathrm{iC}}}\right)^{\mathrm{n}}
$$

where $\mathrm{k}_{0}$ is a factor related to the test conditions and is equal to $3, \mathrm{t}_{0}$ is the reference period and is equal to 1

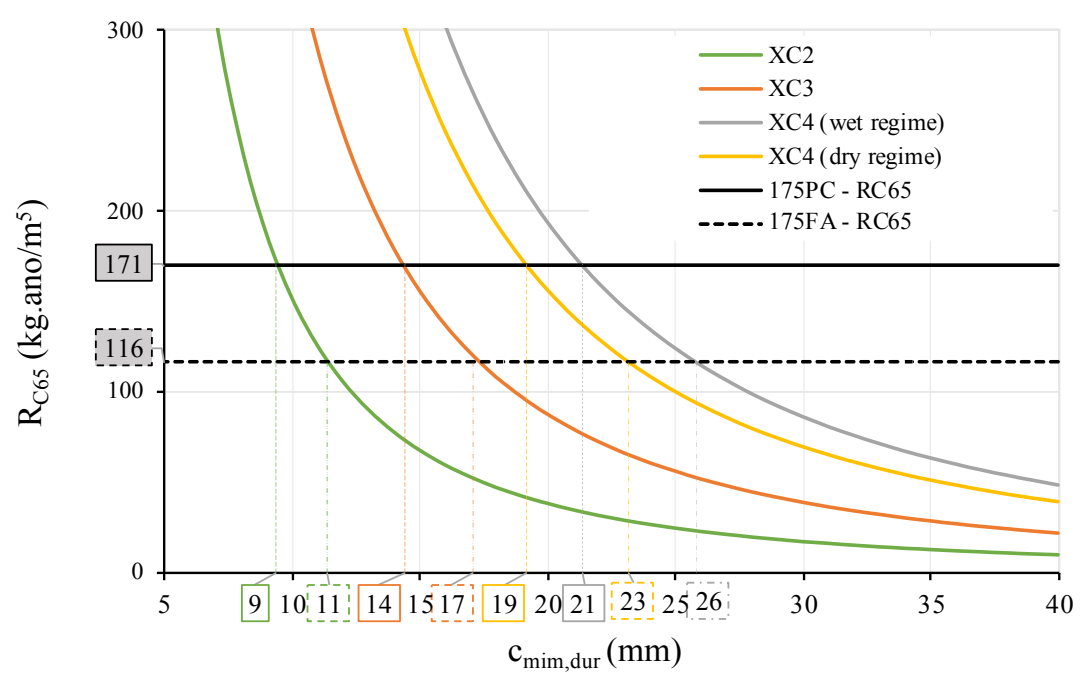

Fig. 16 Minimum cover, $\mathrm{C}_{\mathrm{min}, \mathrm{dur}}$, under the action of carbon dioxide, for current structures (class S4) produced with the studied concretes. 
Table 7 Composition, minimum standards cover, and minimum covers for the studied concrete under the action of $\mathrm{CO}_{2}$.

\begin{tabular}{|c|c|c|c|c|c|c|c|c|c|c|}
\hline & & & \multicolumn{4}{|c|}{ Current structures } & \multicolumn{4}{|c|}{ Special structures } \\
\hline \multicolumn{3}{|c|}{ Type of cement } & \multicolumn{8}{|c|}{ CEM I; CEM II/A (1) } \\
\hline \multicolumn{3}{|c|}{ Exposure class } & $\mathrm{XC} 2$ & $\mathrm{XC} 3$ & $\begin{array}{c}\mathrm{XC4} \\
\text { (dry reg.) }\end{array}$ & $\begin{array}{c}\mathrm{XC4} \\
\text { (wet reg.) }\end{array}$ & $\mathrm{XC} 2$ & $\mathrm{XC} 3$ & $\begin{array}{c}\mathrm{XC} 4 \\
\text { (dry reg.) }\end{array}$ & $\begin{array}{c}\text { XC4 } \\
\text { (wet reg.) }\end{array}$ \\
\hline \multirow{3}{*}{$\begin{array}{l}\text { Minimum cover } \\
\mathrm{c}_{\text {min,dur }}(\mathrm{mm})\end{array}$} & \multicolumn{2}{|c|}{ EC2 } & 25 & 25 & \multicolumn{2}{|c|}{30} & 30 & 30 & \multicolumn{2}{|c|}{35} \\
\hline & \multirow{2}{*}{$\begin{array}{c}\text { Concrete } \\
\text { under study }\end{array}$} & $175 \mathrm{PC}$ & 9 & 14 & 19 & 21 & 13 & 22 & 29 & 31 \\
\hline & & $175 \mathrm{FA}$ & 11 & 17 & 23 & 26 & 15 & 26 & 35 & 37 \\
\hline \multirow{3}{*}{$\begin{array}{c}\text { Minimum dos- } \\
\text { age of C } \\
\left(\mathrm{kg} / \mathrm{m}^{3}\right)\end{array}$} & \multicolumn{2}{|c|}{ EN 206-1 } & 280 & 280 & \multicolumn{2}{|c|}{300} & 280 & 280 & \multicolumn{2}{|c|}{300} \\
\hline & Concrete & $175 \mathrm{PC}$ & \multirow{2}{*}{\multicolumn{8}{|c|}{$\mathrm{C}+\mathrm{k} \cdot(\mathrm{FA}$ or $\mathrm{PC})=205$}} \\
\hline & \multicolumn{2}{|c|}{ EN 206-1 } & & & & & 0.60 & 0.55 & & \\
\hline $\begin{array}{c}\text { Maximum } \mathrm{W} / \mathrm{C} \\
\text { ratio }\end{array}$ & $\begin{array}{c}\text { Concrete } \\
\text { under study }\end{array}$ & $175 \mathrm{PC}$ & \multicolumn{8}{|c|}{$\mathrm{W} /(\mathrm{C}+\mathrm{k} .(\mathrm{FA}$ or $\mathrm{PC}))=0.624$} \\
\hline
\end{tabular}

Table 6 Values of $\mathrm{k}_{1}$ and $\mathrm{n}$ parameters for different exposure classes XC.

\begin{tabular}{|c|c|c|c|}
\cline { 2 - 4 } \multicolumn{1}{c|}{} & XC4 & XC3 & XC2 \\
\hline $\mathrm{k}_{1}$ & 0.41 & 0.77 & 0.20 \\
\hline $\mathrm{n}$ & 0.09 & 0.02 & 0.18 \\
\hline
\end{tabular}

year; $\mathrm{k}_{2}$ is related to curing conditions and was considered equal to 1 , the parameters $\mathrm{k}_{1}$ and $\mathrm{n}$ are defined in Table 6. The minimum cover calculated together with the minimum cover recommended by EC2 are presented in Table 7. The minimum cover, $\mathrm{c}_{\text {min,dur, }}$ using the $175 \mathrm{PC}$ concrete are lower than the minimum value recommended by EC2 and EN 206-1, with differences ranging between 4 and $17 \mathrm{~mm}$, depending on the environmental exposures classes. Those covers are also lower than the $\mathrm{c}_{\text {min,dur }}$ determined using the 175FA concrete, with differences that vary between 3 to $7 \mathrm{~mm}$. For special structures and using the 175FA concrete the covers required are slightly higher than those presented in the standard.

For an overall analysis, where the sustainability concern is taken into consideration, should be noted that the $175 \mathrm{PC}$ contains only $175 \mathrm{~kg} / \mathrm{m}^{3}$ of cement and only 205 $\mathrm{kg} / \mathrm{m}^{3}$ of equivalent cement, which is lower than the minimum standard recommendation of $280 \mathrm{~kg} / \mathrm{m}^{3}$ for $\mathrm{XC} 2$ and $300 \mathrm{~kg} / \mathrm{m}^{3}$ for XC3 and XC4, and cumulatively, the cover required is below the minimum standard, in all cases. So, the quantity of cement can be reduced between $37.5 \%$ to $42 \%$, depending on the environmental exposure classes XC. These results are very important because they have a significant impact on the cost of structures and simultaneously demonstrate that this concrete is clearly more eco-friendly.

\subsubsection{Prediction of the service life of reinforced} concrete structures under the exposure classes XC The prediction of the possible service life for reinforced concrete structures produced using 175PC and 175FA concretes and the covers recommended in the codes was also carried out for several environmental conditions $\mathrm{XC}$ and for both types of structures. That fore, Equation (7) was used to determine the $t_{i c}$ value, knowing the value of the remaining variables and considering $C_{d i}$ equal to the minimum cover presented in the EN 206-1 and EC2. Knowing the $t_{i c}$ and $t_{p}$ values, the service life, $\mathrm{t}_{\mathrm{g}}$, was determined using Equation (6), see Table 8.

Analyzing the Tables $\mathbf{7}$ and $\mathbf{8}$, the developed concretes have a carbonation resistance, $\mathrm{R}_{\mathrm{C} 65}$, more than enough for the exposure class $\mathrm{XC} 2$, having margin to

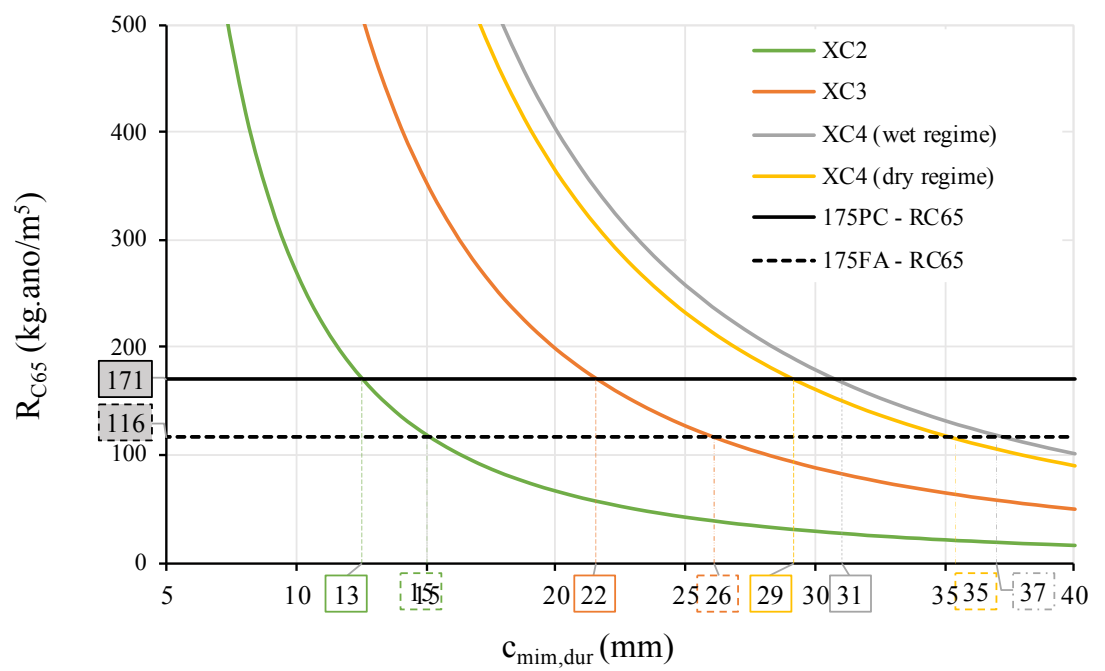

Fig. 17 Minimum cover, $\mathrm{c}_{\mathrm{min} \text {,dur, }}$ under the action of carbon dioxide, for special structures (class S5) produced with the studied concretes. 
Table 8 Service lifetime (years) for current and special structures produced with the studied concrete under environmental conditions XC.

\begin{tabular}{|c|c|c|c|c|c|c|c|c|c|}
\hline & \multicolumn{4}{|c|}{ Current structures (RC2, 50 years) } & \multicolumn{4}{|c|}{ Special structures (RC3, 100 years) } \\
\hline & & $\mathrm{XC} 2$ & $\mathrm{XC} 3$ & $\begin{array}{c}\text { XC4 } \\
\text { (dry reg.) }\end{array}$ & $\begin{array}{c}\text { XC4 } \\
\text { (wet reg.) }\end{array}$ & $\mathrm{XC} 2$ & $\mathrm{XC} 3$ & $\begin{array}{c}\text { XC4 } \\
\text { (dry reg.) }\end{array}$ & $\begin{array}{c}\text { XC4 } \\
\text { (wet reg.) }\end{array}$ \\
\hline Concretes & $\mathrm{c}_{\text {min,dur }}(\mathrm{mm})$ & 25 & 25 & & & 30 & 30 & & \\
\hline $175 \mathrm{PC}$ & $\mathrm{t}_{\mathrm{g}}$ (years) & $>>200$ & 62 & 119 & 109 & $>>200$ & 110 & 144 & 134 \\
\hline $175 \mathrm{FA}$ & $\mathrm{t}_{\mathrm{g}}$ (years) & $>>200$ & 56 & 80 & 70 & $>>200$ & 103 & 98 & 88 \\
\hline
\end{tabular}

Table 9 Values of the minimum propagation periods and the initiation period of calculation due to chloride.

\begin{tabular}{|c|l|c|c|c|}
\cline { 2 - 5 } \multicolumn{2}{c|}{} & XS1 & XS2 & XS3 \\
\hline $\mathrm{t}_{\mathrm{g}}=50$ years & $\mathrm{t}_{\mathrm{p}}$ (years) & 0 & 40 & 0 \\
\cline { 2 - 5 }$(\mathrm{RC} 2)$ & $\mathrm{t}_{\mathrm{ic}}$ (years) & 115 & 24 & 115 \\
\hline $\mathrm{t}_{\mathrm{g}}=100$ years & $\mathrm{t}_{\mathrm{p}}$ (years) & 0 & 80 & 0 \\
\cline { 2 - 5 }$(\mathrm{RC} 3)$ & $\mathrm{t}_{\mathrm{ic}}$ (years) & 280 & 56 & 280 \\
\hline
\end{tabular}

decrease the minimum cover used in reinforced concrete structures. The service life is quite high because in those environmental conditions the carbonation depth, $\mathrm{C}_{\mathrm{d}}$, is very low. Those values also emphasizes that the relation between $\mathrm{C}_{\mathrm{d}}$ and time is not linear. On the other extreme conditions, namely, on exposure class $\mathrm{XC} 4$, the 175FA concrete is not recommended for special structures, since the service life for these structures are less than 100 years. Comparing 175FA and 175PC, it is highly expected that the structures produced with 175PC concrete have a longer service life than those produced with 175FA in all exposure classes, presenting differences between $6 \%$ to $36 \%$, depending on the environmental conditions.

\subsubsection{Determination of minimum cover to resist chloride-induced corrosion}

The calculation of the minimum cover required to assure the proper protection against steel corrosion induced by chlorides is similar to that presented for carbonation, also involving the determination of three parameters: i) the design period of initiation, $t_{i c}$; ii) the diffusion coefficient of chlorides, $\mathrm{D}$, in $\mathrm{m}^{2} / \mathrm{s}$; iii) the penetration depth of chlorides for the various environmental exposure classes XS. The design period of initiation, $t_{i c}$, was determined again using Equation (6), being the propagation period due to chlorides slightly different from those used in carbonation. Those values were considered equal to the minimum value recommended by the LNEC E-465 specification (LNEC E-465 2007). The $t_{p}$ and $t_{i c}$ values are presented in Table 9. The diffusion coefficient of chlorides, $\mathrm{D}$, in $\mathrm{m}^{2} / \mathrm{s}$, decreases with the exposure time according to Equation (8), $\mathrm{k}$ is determined using Equation (9), see Table 10.

$$
\begin{aligned}
& \mathrm{D}=\mathrm{k} \times\left(\frac{\mathrm{t}_{0}}{\mathrm{t}_{\mathrm{iC}}}\right)^{\mathrm{n}} \times \mathrm{D}_{0} \\
& \mathrm{k}=\mathrm{K}_{\mathrm{D}, \mathrm{C}} \times K_{\mathrm{D}, \mathrm{RH}} \times \mathrm{K}_{\mathrm{D} . \mathrm{T}}
\end{aligned}
$$

To determine the $\mathrm{k}$ parameter was considered: i) a
Table 10 Values used in the calculation of the parameter $\mathrm{k}$.

\begin{tabular}{|c|c|c|c|}
\cline { 2 - 4 } \multicolumn{1}{c|}{} & XS1 & XS2 & XS3 \\
\hline $\mathrm{k}_{\mathrm{D}, \mathrm{C}}$ & 2.4 & 0.75 & 2.4 \\
\hline $\mathrm{k}_{\mathrm{D}, \mathrm{RH}}$ & 0.4 & \multicolumn{2}{c|}{1.0} \\
\hline $\mathrm{k}_{\mathrm{D}, \mathrm{T}}$ & \multicolumn{3}{|c|}{0.8} \\
\hline $\mathrm{k}$ & 0.768 & 0.6 & 1.92 \\
\hline
\end{tabular}

normalized curing in exposure classes XS1 and XS3 and curing in permanent contact with water in exposure class XS2; ii) seawater and concrete temperature equal to $15^{\circ} \mathrm{C}$; iii) the worst-case scenario was considered, that is, the structures located next to the coastline; iv) for the structures under exposure class XS2 two situations were considered (structure at $1 \mathrm{~m}$ from sea level; structure between 1.4 to $25 \mathrm{~m}$ in-depth); v) $\mathrm{t}_{0}$, is equal to 28 days; $\mathrm{n}$ depends on the cement type and exposure classes, being equal to 0.55 for XS1 and XS3 and 0.45 for XS2; vi) $D_{0}$ is the potential diffusion coefficient $\left(\mathrm{m}^{2} / \mathrm{s}\right)$ determined in the laboratory tests according to the specification LNEC E-463 (2004), at concrete age $t_{0}=28$ days, whose values are shown in Fig. 13.

Finally, the minimum cover required, herein represented as $\mathrm{R}$, to ensure the protection of reinforcement against corrosion induced by chlorides was determined using Equation (10);

$$
\mathrm{R}=2 \times \xi \sqrt{\mathrm{D} \times \mathrm{t}_{\mathrm{iC}}}
$$

where:

$\xi$ is the error function and is equal to

$$
\xi=\operatorname{erf}^{-1}\left(\frac{\mathrm{C}_{\mathrm{S}}-\mathrm{C}_{\mathrm{R}}}{\mathrm{C}_{\mathrm{S}}}\right)
$$

Equation (10) resulted from Fick's $2^{\text {nd }}$ law model of diffusion and is used to determine the chloride penetration depth. $\mathrm{C}_{\mathrm{S}}$ is the concentration of chlorides on the surface of concrete and $\mathrm{C}_{\mathrm{R}}$ is the concentration of chlorides near the reinforcement. These parameters depend not only on the exposure classes XS but also on the water/cement ratio. The chloride concentration is usually expressed in percentage of chloride content per cement mass, however, according to EN 206-1 (2007), when type II additions are used, the chloride content is expressed as a percentage of chloride ions per mass of cement plus the total mass of type II additions. So, in this study water/(cement + pozzolan or fly ash) ratio was considered, whose value is 0.52 . The $C_{s}$ and $C_{R}$ values are presented in Table 11. The minimum covers 
Table 12 Composition, minimum cover according to standards, and minimum covers for the studied concrete under the action of chlorides.

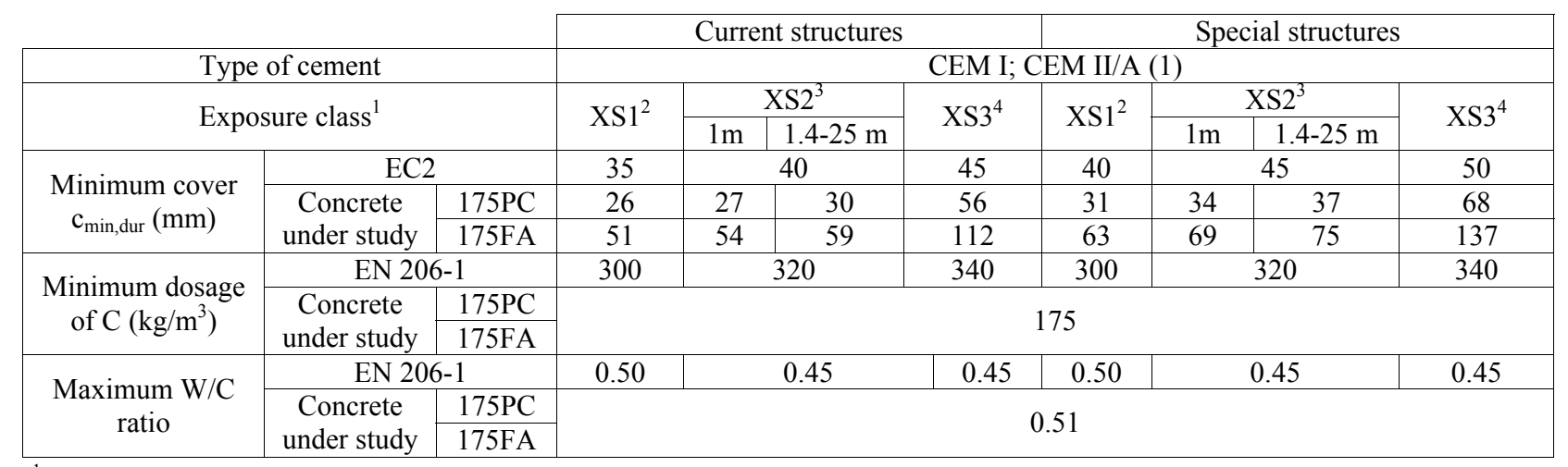

${ }^{1}$ In this analysis, regarding the distance to the coastline, the worst-case scenario was considered (structures are located next to the coastline); ${ }^{2}$ Structures exposed to the air with sea salts; ${ }^{3}$ Structures permanently submerged; ${ }^{4}$ Structures in the tidal zone.

Table 13 Service lifetime (years) for current and special structures produced with the studied concrete under environmental conditions XS.

\begin{tabular}{|c|c|c|c|c|c|c|c|c|c|}
\hline & & \multicolumn{4}{|c|}{ Current structures (RC2, 50 years) } & \multicolumn{4}{|c|}{ Special structures (RC3, 100 years) } \\
\hline & & \multirow{2}{*}{ XS1 } & \multicolumn{2}{|c|}{$\mathrm{XS} 2$} & \multirow{2}{*}{ XS3 } & \multirow{2}{*}{$\mathrm{XS} 1$} & \multicolumn{2}{|c|}{$\mathrm{XS} 2$} & \multirow{2}{*}{$\mathrm{XS} 3$} \\
\hline & & & $1 \mathrm{~m}$ & $1.4-25 \mathrm{~m}$ & & & $1 \mathrm{~m}$ & $1.4-25 \mathrm{~m}$ & \\
\hline Concrete & $t_{p}($ years $)$ & 0 & \multicolumn{2}{|r|}{40} & 0 & 0 & \multicolumn{2}{|r|}{80} & 0 \\
\hline \multirow{2}{*}{$175 \mathrm{PC}$} & $\mathrm{t}_{\mathrm{ic}}$ (years) & 204 & 42 & 31 & 19 & 304 & 53 & 39 & 25 \\
\hline & $\mathrm{t}_{\mathrm{g}}$ (years) & $>200$ & 82 & 71 & 19 & $\gg>200$ & 133 & 119 & 25 \\
\hline \multirow{2}{*}{$175 \mathrm{FA}$} & $\mathrm{t}_{\mathrm{ic}}$ (years) & 9 & 3 & 2 & 1 & 14 & 4 & 3 & 1 \\
\hline & $t_{\mathrm{g}}$ (years) & 9 & 43 & 42 & 1 & 14 & 84 & 83 & 1 \\
\hline
\end{tabular}

Table 11 Values used in the calculation of $\mathrm{Cs}$ and $\mathrm{C}_{\mathrm{R}}$ parameter.

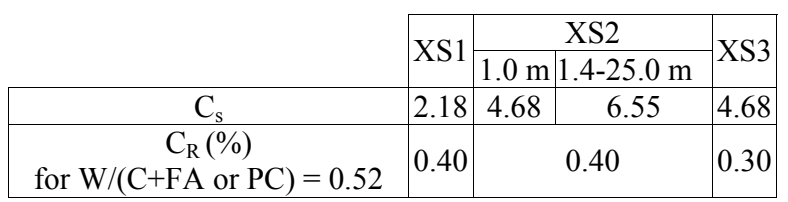

calculated are shown in Table 12, together with the minimum cover recommended by EC2.

For the same service life and type of structures, the minimum cover increases with an increase of the environmental exposure class and the chloride diffusion coefficient. When the two studied concretes were compared, the minimum covers required using 175FA are approximately $50 \%$ higher than those obtained with $175 \mathrm{PC}$ concrete, in both types of structures and for all $\mathrm{XS}$ environmental conditions. The $175 \mathrm{PC}$ concrete has a minimum cover below the minimum value recommended by EC2, with differences of $19 \%, 24 \%$, and $18 \%$ for current structures and for the conditions XS1, $\mathrm{XS} 2$ at $1 \mathrm{~m}$ from sea level, and XS2 at 24m depth, respectively. These differences diminish for special structures, becoming $14 \%, 15 \%$, and $10 \%$, respectively. For class XS3 and for the same concrete, the opposite is verified, now the minimum covers required are higher than the standards values, in both types of structures, with differences of $10 \%$ and $13 \%$ for current and special structures, respectively. For the 175FA, the minimum covers required are found to be higher than the mini- mum values recommend by codes, for both types of structures and for all classes of XS exposures.

It can be concluded that $175 \mathrm{PC}$ concrete is more suitable for resisting chloride penetration than 175FA concrete. The results show a margin to decrease the minimum cover defined in EC2, for both types of structures, particularly for structures located in environmental conditions XS1 and XS2. However, this concrete has a limited performance for very aggressive regions, tidal zones (XS3). In those conditions, is required higher covers that are not used in current situations. The 175FA concrete is not recommended to be used in structures under the environment XS. If it is intended to use this concrete, it would be necessary to adopt concrete covers well above the minimum standards or provide special protective coatings.

\subsubsection{Prediction of the service life of reinforced} concrete structures under the exposure classes XS The predictions of the service life for reinforced concrete structures, $t_{\mathrm{g}}$, shown in Table 13, were determined using the concrete covers recommended by codes, the $t_{p}$ values already presented, and calculating the corresponding $t_{i c}$ values. Current and special should have a service life at least of 50 and 100 years, respectively. Using 175PC concrete and adopting the minimum standard cover, the service life of these structures can increase considerably in some environmental conditions, such as XS1 and XS2. This result may represent an economic benefit since maintenance is likely to occur later 
than expected. These results confirm the conclusions of previous section, i.e., the $175 \mathrm{PC}$ is not recommended for structures located in environmental exposures XS3 and the 175FA is not suitable to be used in environmental conditions XS.

\section{Conclusions}

This research is focused on the study of the influence of natural pozzolans (from Cape Verde and the Azores), as an alternative to fly ash in the mechanical and durability performance of low cement concrete (LCC). Several LCC mixtures were formulated and characterized containing high volumes of replacement of cement by additions: $50 \%$ and $64 \%$ by mass of the total binder powder, setting the limestone filler dosage at $100 \mathrm{~kg} / \mathrm{m}^{3}$ and varying the proportions of fly ash or natural pozzolans between $21 \%$ to $36 \%$ to fulfill the total binder of 350 $\mathrm{kg} / \mathrm{m}^{3}$. From the experimental results and analysis, the following conclusions are drawn:

(1) Fly ash provides better workability to the mixtures than the pozzolan additions from Azores and Cape Verde. Pozzolan from the Azores requires a higher dosage of superplasticizer and water, consequently resulting in mixtures with slightly lower compactness and higher porous structure.

(2) Pozzolan from Cape Verde promotes higher compressive strengths of concrete at all ages, from $5 \%$ to $8 \%$, than those with fly ash addition, and from $1 \%$ to $18 \%$ higher than those with pozzolan from the Azores.

(3) It is possible to improve the hardening curves of the LCC based on the optimization of its matrix, thus mitigating the limitations of the use of high dosages of additions. The LCC mixtures with pozzolan from Cape Verde and with fly ash that containing $50 \%$ of additions, present a curve close to that of normal hardening, although with earlier hardening $(\mathrm{sc}=0.3)$, proving that LCC mixtures can be produced and optimized mitigating the limitations of high dosages of additions.

(4) The replacement of fly ash by pozzolan additions from Azores and Cape Verde causes a slight reduction of Young's modulus, between $1 \%$ to $6 \%$, when replaced by pozzolan from Cape Verde and between $11 \%$ to $14 \%$ when replaced by pozzolan from the Azores.

(5) The increase of the replacement rate of fly ash by natural additions by more than $50 \%$ tends to decrease the tensile strength. The maximum loss of $22 \%$ was registered in concrete with a higher dosage of pozzolan from Cape Verde (65\%).

(6) The capillary absorption coefficients of concrete with fly ash (175FA) and concrete with pozzolan from Cape Verde (175PC) allow to consider both concrete as high quality. The pozzolan from Cape Verde promotes a reduction of water absorption up to $36 \%$, which is higher than that in concrete with fly ash.

(7) Regarding carbonation resistance, the pozzolan from Cape Verde has a positive influence on reducing the carbonation comparatively to fly ash, being the carbonation coefficient of the 175PC approximately $15 \%$ lower than that of 175FA.

(8) The chloride diffusion coefficient of LCC with Cape Verde pozzolan is 4 to 6 times lower than that of LCC with fly ash (note that this difference changes with age). Considering that the chloride ion migration through the matrix is highly dependent of the open porous network, these results, as well as the hardening curve, can be attributed to the higher pozzolanic activity of the pozzolan comparatively to the fly ash. The additional formation of C-S-H and the consequent refinement of the microstructure may explain the differences between the diffusion coefficients and how they evolve over time: in 175PC the diffusion coefficient decreases only $17 \%$, between 28 and 56 days, and $60 \%$, between 56 and 90 days, and; in 175FA it decreases circa $43 \%$, between 28 and 56 days, and $17 \%$, between 56 and 90 days of age.

This research proves that the addition of pozzolan from Cape Verde as replacement of Portland cement is very effective, in comparison to fly ash, regarding the pozzolanic effect on the improvement of both strength and durability performance of concretes with low cement content. The structures produced with the developed concrete require a minimum cover lower than the values recommended by main codes, for almost all exposure classes $\mathrm{XC}$ and $\mathrm{XS}$, being the exception the very aggressive conditions on tidal zones (XS3). Initially a readjustment of national standards and legally mandatory use of local materials in public contracts will be required, but it is expected that the construction industry will gradually evolve for a generalize application of concrete with natural pozzolan, valuing local materials and taking advantageous of this solution from different points of view, technical, economic and environmental points of view. The use of local material is highly sustainable since the impact associated to their transportation is very reduced. Nevertheless, these pozzolans can also be used in other foreign countries, mainly in those that do not produce cement and therefore have to import it, once the environmental impact of using pozzolans (as cement replacement) is lower than the impact of using cement. A sustainability analysis is being conducted and will be addressed in a future publication, focusing this subject.

\section{Acknowledgments}

The authors acknowledge the Calouste Gulbenkian Foundation, for the Doctoral Grant, with the reference SBG35-2016, the Polytechnic Institute of Coimbra, ISEC, for providing the facilities and all necessary resources to perform the present study, and CERIS. 


\section{References}

AASHTO T358-15, (2015). "Standard method of test for surface surface resistivity indication of concrete's ability to resist chlorideion penetration." Washington: American Association of State Highway and Transportation Officials.

ACI Committee 232, (2000). "Use of raw or processed natural pozzolans in concrete reported by ACI committee 232." ACI Manual of Concrete Practice., American Concrete Institute, MI USA: Farmington Hills.

Bentz, D. P., Hansen, A. S. and Guynn, J. M., (2011). "Optimization of cement and fly ash particle sizes to produce sustainable concretes." Cement and Concrete Composites, 33(8), 824-831.

Bentz, D. P., Sato, T., de la Varga, I. and Weiss, W. J., (2012), "Fine limestone additions to regulate setting in high volume fly ash mixtures." Cement and Concrete Composites, 34(1), 1-17.

Björnström, J. and Chandra, S., (2003). "Effect of superplasticizers on the rheological properties of cements." Materials and Structures, 36(264), ,685692.

Browne, R., (1991). "Field investigations: Site \& laboratory tests: Maintenance repair and rehabilitation of concrete structures." Lisboa: CEEC.

Cost, V. and Aci, F., (2011). "Concrete sustainability versus constructability - Closing the gap." In: Proceedings of International Concrete Sustainability Conference, Boston, 1-15.

Costa, A. and Appleton, J., (1999). "Chloride penetration in reinforced concrete structures exposed to marine environment." Revista Portuguesa de Engenharia de Estruturas, 1, 46.

Costa, H., (2012). "Structural concretes of light aggregates, Applications in rrefabrication and reinforcement of structures." Thesis (PhD). University of Coimbra. (in Portuguese)

Coutinho, J. S., (2005). "Improving the durability of concrete by treating formwork." 1st ed., Porto: FEUP. (in Portuguese)

De Grazia, M., Sanchez, L., Romano, R. and Pileggi, R., (2019). "Investigation of the use of continuous particle packing models (PPMs) on the fresh and hardened properties of low-cement concrete (LCC) systems." Construction and Building Materials, 195, 524-536.

Dinakar, P., Babu, K. and Santhanam, M., (2008). "Durability properties of high volume fly ash self compacting concretes." Cement and Concrete Composites, 30(10), 880-886.

EN 1015-3, (1998). "Methods of test for mortar for masonry - Part 3: Determination of consistence of fresh mortar (by flow table)." Brussels, Belgium: European Committee for Standardization (CEN).

EN 1015-6, (1998). "Methods of test for mortar for masonry. Part 6: Determination of bulk density of fresh mortar." Brussels, Belgium: European Committee for Standardization (CEN).

EN 1015-7, (1998). "Methods of test for mortar for masonry - Part 7: Determination of air content of fresh mortar." Brussels, Belgium: European Committee for Standardization (CEN).

EN 12390-3, (2009). "Testing hardened concrete Part 3: Compressive strength of test specimens." Brussels, Belgium: European Committee for Standardization (CEN)

EN 12390-5, (2009). "Testing hardened concrete Part 5: Flexural strength of test specimens." Brussels, Belgium: European Committee for Standardization (CEN).

EN 12390-6, (2009). "Testing hardened concrete - Part 6: Tensile splitting strength of test specimens." Brussels, Belgium: European Committee for Standardization (CEN).

EN 14629, (2007). "Products and systems for the protection and repair of concrete structures - Test methods - Determination of chloride content in hardened concrete." Brussels, Belgium: European Committee for Standardization (CEN).

EN 1992-1-1, (2010). "Eurocode 2 - Design of concrete ctructures Part 1-1: General rules and rules for buildings." Brussels, Belgium: European Committee for Standardization (CEN).

EN 206-1, (2007). "Concrete - Part 1: Specification, performance, production and conformity." Brussels, Belgium: European Committee for Standardization (CEN).

Fennis, S., (2011). "Design of ecological concrete by particle packing optimization." Delft University of Technology. Available at: http://repository.tudelft.nl/ assets/uuid:5a1e445b-36a7-4f27-a89a-d48372d2a45c/ fennis_final.pdf Féret.

Fennis, S. and Walraven, J., (2012). "Using particle packing technology for sustainable concrete mixture design" Heron, 57(2), 73-101.

Fennis, S., Walraven, J. and Uijl, J., (2009). "The use of particle packing models to design ecological concrete." Heron, 54(2/3), 185-204.

Fennis, S., Walraven, J. and Uijl, J., (2013a). "Compaction-interaction packing model: regarding the effect of fillers in concrete mixture design." Materials and Structures, 46(3), 463-478.

Fennis, S., Walraven, J. and Uijl, J., (2013b). "Definedperformance design of ecological concrete." Materials and Structures, 46(4), 639-650.

Gjorv, O. E., (1996). "Performance and serviceability of concrete structures in the marine environment." In: P. K Mehta Ed. Proceedings of Symposium on Concrete for Marine Structures, ACI/CANMET, Ottawa, 259279.

Jiang, L. and Malhotra, V., (2000). "Reduction in water demand of non-air-entrained concrete incorporating large volumes of fly ash." Cement and Concrete Research, 30(11), 1785-1789.

LNEC E-393, (1993). "Concrete. determination of the absorption of water through capillarity." Lisboa, 
Portugal: National Laboratory of Civil Engineering (LNEC). (In Portuguese)

LNEC E-397, (1993). "Hardened concrete - Determination of the modulos of elasticity of concrete in compression." Lisboa, Portugal: National Laboratory of Civil Engineering (LNEC). (In Portuguese)

LNEC E-463, (2004). "Determination of diffusion coefficient of chlorides from non-steady-state migration test." Lisboa, Portugal: National Laboratory of Civil Engineering (LNEC). (In Portuguese)

LNEC E-465, (2007). "Concrete. methodology for estimating the concrete performance properties allowing to comply with the design working life of the reinforced or prestressed concrete structures under the environmental exposures $X C$ and XS." Lisboa, Portugal: National Laboratory of Civil Engineering (LNEC). (In Portuguese)

Lourenço, J., Júlio, E. and Maranha, P., (2004). "Expanded clay lightweight aggregate concrete." Lisbon: APEB. (in Portuguese)

Mehta, P., (2004). "High-performance, high-volume fly ash concrete for sustainable development." In: Kejin Wang, Ed. Proceedings of International Workshop on Sustainable Development and Concrete Technology, Beijing China 20-21 May 2004. Iowa USA: Center for Transportation Research and Education Iowa State University, 3-14.

Mehta, P. K. and Monteiro, P. J. M., (2014). "Concrete: microstructure, properties, and materials." 4th ed., New York: McGraw-Hill Education.

Meyer, C., (2009). "The greening of the concrete industry." Cement and Concrete Composites, 31(8), 601-605.

Nasvik, J., (2013). "Sustainable concrete structures How to use concrete for sustainable purposes." Concrete Construction, 2, 765-780.

Nordtest, (1984). "Concrete, repairing materialsand protective coating: Carbonation resistance, (NT Build 357)." Avaldsnes, Norway: Nordtest.

Nordtest, (1999). "Nordtest method for concrete, mortar and cement-based repair materials: Chloride migration coefficient from Non-Steady-State migration experiments, (NT Build 492)." Measurement, Avaldsnes, Norway:
Nordtest, 1-8.

Germann Instrument, (2015). "Chloride penetration in concrete. Short overview and available instruments." Available from: <http:/www.germann.org/TestSystems/ PROOVEit/Chloride\%20Penetration\%20Overview.pd $\mathrm{f}>$

Proceq, (2017). "Operating instructions concrete durability testing." Switzerland: Proceq SA.

Proske, T., Hainer, S., Rezvani, M. and Graubner, C., (2014). "Eco-friendly concretes with reduced water and cement content - Mix design principles and application in practice." Construction and Building Materials Journal, 67(Part C), 413-421.

Proske, T., Hainer, S., Rezvani, M. and Graubner, C., (2016). "Eco-friendly concretes with reduced water and cement content: mix design principles and experimental tests." Construction and Building Materials Journal, 67(Part C), 63-87.

Robalo, K., Soldado, E., Costa, H., do Carmo, R., Alves, H. and Júlio, E., (2021). "Efficiency of cement content and of compactness on mechanical performance of low cement concrete designed with packing optimization." Construction and Building Materials, 266, 121077.

Rodríguez-Camacho, R. and Uribe-Afif, R., (2002). "Importance of using the natural pozzolans on concrete durability." Cement and Concrete Research, 32(12), 1851-1858.

Teixeira, E., Branco, F. and Camões, A., (2018). "Ecoefficient concrete study through the use of biomass fly ash." 3rd Luso-Brazilian Congress on Sustainable Construction Materials, Coimbra. (in Portuguese)

Thomas, M., Hooton, R., Scott, A. and Zibara, H., (2012). "The effect of supplementary cementitious materials on chloride binding in hardened cement paste." Cement and Concrete Research, 42(1), 1-7.

Uzal, B. and Turanli, L., (2003). "Studies on blended cements containing a high volume of natural pozzolans." Cement and Concrete Research, 33(11), 1777-1781.

Uzal, B., Turanli, L. and Mehta, P. K., (2007). "Highvolume natural pozzolan concrete for structural applications." ACI Materials Journal, 104(5), 535-538. 